\title{
How does cellulosome composition influence deconstruction of lignocellulosic substrates in Clostridium (Ruminiclostridium) thermocellum DSM 1313?
}

Shahar Yoav ${ }^{1,2}$, Yoav Barak ${ }^{3}$, Melina Shamshoum4, Ilya Borovok ${ }^{5}$, Raphael Lamed ${ }^{5}$, Bareket Dassa ${ }^{4}$, Yitzhak Hadar', Ely Morag ${ }^{4}$ and Edward A. Bayer ${ }^{4 *}$ (D)

\begin{abstract}
Background: Bioethanol production processes involve enzymatic hydrolysis of pretreated lignocellulosic biomass into fermentable sugars. Due to the relatively high cost of enzyme production, the development of potent and costeffective cellulolytic cocktails is critical for increasing the cost-effectiveness of bioethanol production. In this context, the multi-protein cellulolytic complex of Clostridium (Ruminiclostridium) thermocellum, the cellulosome, was studied here. C. thermocellum is known to assemble cellulosomes of various subunit (enzyme) compositions, in response to the available carbon source. In the current study, different carbon sources were used, and their influence on both cellulosomal composition and the resultant activity was investigated.
\end{abstract}

Results: Glucose, cellobiose, microcrystalline cellulose, alkaline-pretreated switchgrass, alkaline-pretreated corn stover, and dilute acid-pretreated corn stover were used as sole carbon sources in the growth media of C. thermocellum strain DSM 1313. The purified cellulosomes were compared for their activity on selected cellulosic substrates. Interestingly, cellulosomes derived from cells grown on lignocellulosic biomass showed no advantage in hydrolyzing the original carbon source used for their production. Instead, microcrystalline cellulose- and glucose-derived cellulosomes were equal or superior in their capacity to deconstruct lignocellulosic biomass. Mass spectrometry analysis revealed differential composition of catalytic and structural subunits (scaffoldins) in the different cellulosome samples. The most abundant catalytic subunits in all cellulosome types include Cel48S, Cel9K, Cel9Q, Cel9R, and Cel5G. Microcrystalline cellulose- and glucose-derived cellulosome samples showed higher endoglucanase-to-exoglucanase ratios and higher catalytic subunit-per-scaffoldin ratios compared to lignocellulose-derived cellulosome types.

Conclusion: The results reported here highlight the finding that cellulosomes derived from cells grown on glucose and microcrystalline cellulose are more efficient in their action on cellulosic substrates than other cellulosome preparations. These results should be considered in the future development of $C$. thermocellum-based cellulolytic cocktails, designer cellulosomes, or engineering of improved strains for deconstruction of lignocellulosic biomass.

Keywords: Lignocellulosic biomass, Proteomics, Enzymatic hydrolysis, Scaffoldins, Biofuels

\footnotetext{
*Correspondence: ed.bayer@weizmann.ac.il.

${ }^{4}$ Department of Biomolecular Sciences, The Weizmann Institute

of Science, 76100 Rehovot, Israel

Full list of author information is available at the end of the article
} 


\section{Background}

Developing cost-effective and renewable alternative energy resources capable of replacing currently used fossil fuel is an important challenge [1]. Cellulosic ethanol, one of the suggested solutions of this global issue, meets the necessary requirements of being renewable and environmentally friendly $[2,3]$. Unlike the production process of the first-generation bioethanol alternative, which utilizes the edible parts of plants, the cellulosic ethanol alternative exploits the inedible polysaccharides of the plant, notably the cellulose, found in the cell walls of lignocellulosic biomasses [4,5]. Agriculture or industrial lignocellulosic wastes can be used as sources of biomass, although removal of plant residues from the field could also have negative effects on soil fertility and quality [6].

The plant cell wall is a chemically complex structure composed of cellulose, hemicelluloses, and lignin as the main polymers. Those polymers, together with other components, provide the plant cell with the robustness required for its diverse functions $[7,8]$.

The production process for converting cellulosic biomass to ethanol involves three major steps [2]. The first includes chemical or physical pre-treatment, which is designed to loosen the rigid structure of the plant cell wall, to increase cellulose accessibility and to enrich the cellulose fraction. In the second step, the enriched cellulose fraction is hydrolyzed into soluble fermentable sugars. In the third step, the soluble sugar mixture is used as a carbon source for alcoholic fermentation. To date, the hydrolysis step is performed by enzymatic hydrolysis, rendering cellulosic ethanol economically infeasible, mainly due to the relatively high production costs of the carbohydrate-hydrolyzing enzymes $[9,10]$.

Cellulolytic microorganisms can utilize the cellulose as a carbon source. The natural arsenal of plant cell walldegrading enzymes is diverse, and includes cellulases, hemicellulases, pectinases, ligninases, and additional accessory enzymes. Cellulose-hydrolyzing enzymes are classified into three major groups by their sequence homology and biochemical characteristics: (A) endoglucanases, which cleave bonds in the middle of the cellulose chains in random or semi-random fashion; (B) exoglucanases, which hydrolyze cellulose from either the reducing or non-reducing end in a processive manner, releasing soluble non-monomeric sugars; and (C) $\beta$-glucosidases, which hydrolyze the end-product (cellobiose) of cellulase hydrolysis to produce glucose $[11,12]$.

Clostridium thermocellum (recently reclassified as Ruminiclostridium thermocellum) is one of the bestexplored and well-characterized cellulose-degrading bacteria in nature. Due to its characteristics, this anaerobic thermopilic bacterium was suggested to be the organism of choice for bioethanol production processes [13-17]. Its cellulolytic machinery, called cellulosome, is a multi-protein complex that contains a multiplicity of catalytic subunits, as well as structural proteins (scaffoldins) which are responsible for integrating the catalytic subunits into a well-ordered high-molecular-weight complex [14, 18]. Selected scaffoldins can bind cellulose by virtue of an integral cellulose-binding module (CBM), which are attached to the bacterium via an anchoring protein that contains an S-layer homology (SLH) module [19]. In this manner, the cellulosome creates proximity and substrate-targeting effects [20]. There are more than eighty genes in the genome of $C$. thermocellum that encode for cellulosomal subunits [21]. In addition to the cellulosome, $C$. thermocellum also utilizes soluble noncellulosomal cellulolytic enzymes for deconstruction of cellulose [22-24].

The composition and structure of plant cell walls differ among different plant species as well as among different tissues in a given plant. In addition to their inherent variability, different pre-treatments can further alter the composition of the lignocellulosic biomass, leading to even higher diversity among the carbon sources used in the bioethanol production process [8]. Consequently, different enzyme compositions might be required for efficient hydrolysis of the different carbon sources. Indeed, proteomic and transcriptomic studies have shown that the expression pattern of the cell wall-degrading enzymes and the composition of the cellulosomes change in response to the carbon source of the medium. In other words, $C$. thermocellum senses the biomass in the medium and assembles a cellulosome preparation tailored to the requirements of the bacterium. Former studies have highlighted the need for understanding differential assembly of cellulosomal subunits in order to reveal key enzymes that are important for efficient hydrolysis [25-28].

In the current study, cellobiose $(\mathrm{CB})$, microcrystalline cellulose (MCC), alkaline-pretreated switch grass (alSG), alkaline-pretreated corn stover (alCS), and dilute acidpretreated corn stover (acCS), were used as sole carbon sources for growth of C. thermocellum DSM1313. In nature, $C$. thermocellum hydrolyzes cellulose into cellobiose units, which are in turn consumed by the bacterium. An adaptation process can enable some $C$. thermocellum strains to utilize monomeric glucose as a sole carbon source [13, 29-31]. In this study, such an adaptation process was conducted, and glucose was also used as a sole carbon source. The influence of various carbon sources on the structure and subunit composition of the resultant cellulosomes, and consequently on its hydrolysis activity, was investigated. 


\section{Methods}

Alkaline pre-treatment of corn stover and switchgrass

Corn stover was collected after harvest from Moshav Kfar HaRif, Israel. Switchgrass was obtained from Notts Farms, Clinton, ON, Canada. Alkaline pre-treatment was carried out as previously described [32]. Briefly, $100 \mathrm{~g}$ of each feedstock were separately placed into 2-L glass beakers followed by the addition of $700 \mathrm{~mL}$ of $2 \%$ [wt/wt] $\mathrm{NaOH}$ solution. The beakers containing biomass and alkali solution were heated to boiling and allowed to proceed under this temperature for $1 \mathrm{~h}$ with continuous stirring. The pretreated biomasses were then washed by water through a glass Buchner funnel and adjusted to neutral $\mathrm{pH}$. Finally, the pretreated biomasses were drained using vacuum through the funnel and brought to about $20-30 \%(w t / w t)$ solid content.

\section{Dilute acid-pretreated corn stover}

Dilute sulfuric acid-pretreated corn stover $\left(160{ }^{\circ} \mathrm{C}\right.$ for $1 \mathrm{~min}$ at an effective acid concentration of $1-2 \%[\mathrm{w} / \mathrm{w}]$ ) was obtained from the National Renewable Energy Laboratory (NREL), Golden, CO (Batch Number P080828CS-8. Manufactured: 26.11.13; Record No. 579).

\section{Chemical composition of biomass}

The chemical composition of the various biomasses was determined by conventional chemical analysis methods $[33,34]$. Briefly, for delignification, the desired lignocellulosic biomass (1\% slurry [w/v]) was supplemented with $1 \%$ acetic acid $[\mathrm{v} / \mathrm{v}]$ and $1.5 \%[\mathrm{w} / \mathrm{v}]$ sodium chlorite and boiled for $1 \mathrm{~h}$. The delignification process was then repeated. The obtained (white) holocellulose, i.e., complex of cellulose and hemicelluloses, was hydrolyzed by boiling in $1.5 \%$ hydrochloric acid for $2 \mathrm{~h}$. The content of cellulose was calculated from the dry residue remaining after hydrolysis of the holocellulose, while the content of hemicelluloses was measured from weight loss of the hydrolyzed holocellulose sample. Lignin Klason was analyzed by means of standard TAPPI procedure T222 [34].

\section{Anaerobic fermentation of $C$. thermocellum}

Growth of the anaerobic thermophilic bacterium C. thermocellum (strain DSM 1313 obtained from the DSMZ collection) was performed as previously described [35] with minor changes. Briefly, GS-2 medium $(0.5 \mathrm{~g} / \mathrm{L}$ $\mathrm{K}_{2} \mathrm{HPO}_{4}, 0.5 \mathrm{~g} / \mathrm{L} \mathrm{MgCl}_{2} \cdot 6 \mathrm{H}_{2} \mathrm{O}, 0.5 \mathrm{~g} / \mathrm{L} \mathrm{K \textrm {K } _ { 2 }} \mathrm{PO}_{4}, 1.3 \mathrm{~g} / \mathrm{L}$ $(\mathrm{NH} 4)_{2} \mathrm{SO}_{4}, 0.002 \mathrm{~g} / \mathrm{L}$ resazurin, $10.5 \mathrm{~g} / \mathrm{l}$ 3-(N-morpholino) propanesulfonic acid (MOPS) buffer, $5 \mathrm{~g} / \mathrm{L}$ yeast extract, $0.5 \mathrm{mM} \mathrm{CaCl}_{2}$, and $1.25 \mathrm{mg} / \mathrm{L}$ iron(II) sulfate) was adjusted with $10 \mathrm{M} \mathrm{NaOH}$ to a final $\mathrm{pH}$ of 7.2. A portion $(400 \mathrm{~mL})$ of the medium was transferred into $0.5 \mathrm{~L}$ serum bottles containing $0.3 \%$ (wt/vol) of the different carbon sources (except $0.5 \%$ in the case of glucose), boiled, and extensively flushed with nitrogen. The bottles were sealed, autoclaved $\left(121^{\circ} \mathrm{C}, 20 \mathrm{~min}\right)$, and inoculated with a fresh CB-based $C$. thermocellum starter culture. For inoculation of glucose-containing media, a preliminary adaptation process was performed. Glucose-based media were thus inoculated with $C$. thermocellum followed by seven successive re-inoculation steps, which resulted in significant shortening of the lag phase rendering it comparable to the that of cellobiose-based growth media. Triplicate samples were prepared. Bottles were incubated for $48 \mathrm{~h}$ in a $60{ }^{\circ} \mathrm{C}$ shaking incubator.

\section{Cellulosome purification}

C. thermocellum growth media were centrifuged $(10,900 \mathrm{~g}, 7 \mathrm{~min})$, and the supernatant fluids were carefully removed from the pellet and concentrated 40 times using a Pellicon XL biomax 300 cassette (Millipore, Cat. No. PXB300C50). Concentrated samples were fractionated by size exclusion chromatography using a Superdex S-200 prep grade 16/60 gel filtration column (GE Healthcare). Fractions $(1 \mathrm{~mL})$ were collected and analyzed by $6 \%$ SDS-PAGE. Fractions containing the cellulosomes (scaffoldin and identified enzymatic subunits) were pooled (Additional file 1: Figure S1). Cellulosome concentration was determined using a Pierce ${ }^{\mathrm{TM}}$ BCA Protein Assay Kit (Thermo scientific, Waltham, MA). Since samples from cellobiose- and glucose-based media showed relatively low concentrations, they were further concentrated by Vivaspin (Sartorius, Goettingen, Germany) with polyethylene sulfate (PES) membrane (30,000 MWCO). Samples were stored at $-20^{\circ} \mathrm{C}$ until use.

\section{$\beta$-glucosidase}

Thermoanaerobacter brockii thermostable $\beta$-glucosidase, CglT (GenBank: ADV80605.1), was a kind gift of CelDezyner LTD, Israel (alon@celdezyner.com). The concentration of CglT in the unpurified sample was determined based on comparative activity tests $(1 \mathrm{~mL}$ of $50 \mathrm{mM}$ sodium citrate buffer, $\mathrm{pH} 6.0$, containing $5 \mathrm{mM}$ $p$-nitrophenyl- $\beta$-D-1, 4-glucopyranoside [Sigma-Aldrich, Rehovot, Israel] was supplemented with $5 \mu \mathrm{L}$ CglT sample dilutions, followed by incubation at $60{ }^{\circ} \mathrm{C}$ for $10 \mathrm{~min}$. Optical densities were measured at a wavelength of $405 \mathrm{~nm}$ and compared to that of an assay mixture containing purified CglT.

\section{Activity assay}

All activities assays were conducted in a final volume of $1 \mathrm{~mL}$ solution, containing $20 \mathrm{mM}$ citrate buffer ( $\mathrm{pH}$ 6.0) supplemented with $10 \mathrm{mM} \mathrm{CaCl}$, and substrate loadings of $7 \%$ for the MCC hydrolysis assay or $5 \%$ for the lignocellulosic biomasses. Cellulosome loadings of 20, 50, 3, or $50 \mu \mathrm{g} / \mathrm{mL}$ were used for MCC, alSG, alCS, and acCS 
hydrolysis assays, respectively. The latter concentrations were found to be in the near-linear range of the reactions, as determined by preliminary calibration experiments (Additional file 2: Figure S2). CglT (equivalent to $0.33 \mathrm{mg} / \mathrm{mL}$ of purified enzyme) was added to the reaction mixture in order to prevent cellobiose feedback inhibition. To evaluate the activities, samples were incubated overnight at $70{ }^{\circ} \mathrm{C}$ with continuous shaking, centrifuged, and the supernatant fluids were separated from the undigested biomass. Released soluble sugar (reducing end) concentrations were analyzed by the dinitrosalicylic acid (DNS) method, as previously described [36]. Final soluble sugar concentrations were determined against a glucose calibration curve, and specific activity $[\mu \mathrm{M}$ reducing ends $\left.(\mu \mathrm{g} \text { protein })^{-1} \mathrm{~min}^{-1}\right]$ was calculated.

\section{Proteolysis}

The purified cellulosome samples were dissolved in $8 \mathrm{M}$ urea in $100 \mathrm{mM}$ ammonium bicarbonate, reduced by dithiothreitol at a final concentration of $2.8 \mathrm{mM}\left(60{ }^{\circ} \mathrm{C}\right.$ for $30 \mathrm{~min}$ ) and modified with $8.8 \mathrm{mM}$ iodoacetamide in $100 \mathrm{mM}$ ammonium bicarbonate (30 min, room temperature, in the dark). The reduced, modified samples were then digested by modified trypsin (Promega, Madison, WI) at a 1:50 enzyme-to-substrate ratio in $2 \mathrm{M}$ urea, $25 \mathrm{mM}$ ammonium bicarbonate, overnight, followed by a second digestion step $(4 \mathrm{~h})$.

\section{Mass spectrometry analysis}

Following the digestion step, the resultant peptide mixture was desalted, dried, and re-suspended in $0.1 \%$ formic acid. The peptides were resolved by reverse-phase chromatography on $0.075 \times 180$-mm fused silica capillaries (J\&W) packed with Reprosil reversed phase material (Dr. Maisch GmbH, Germany). The peptides were eluted with a linear 60 -min gradient of $5-28 \%$ acetonitrile with $0.1 \%$ formic acid, 5-min gradient of $28-95 \%$, and $15 \mathrm{~min}$ at $95 \%$ acetonitrile with $0.1 \%$ formic acid in water, at a flow rate of $150 \mathrm{~nL} / \mathrm{min}$. MS analysis was performed by Q Exactive plus mass spectrometer (Thermo Scientific, Waltham, MA) in a positive mode using repetitively full MS scan followed by collision-induced dissociation (CID) of the ten most dominant ions selected from the first MS scan. The MS data were analyzed using MaxQuant v1.5.1.2 software (Cox and Mann [37]) versus the $C$. thermocellum DSM1313 section of the NCBI-nr database with 1\% FDR, and further analyzed against the Carbohydrate-Active enzymes (CAZY) database. Due to the repetitive nature of some cellulosomal subunit sequences, we considered only proteins identified by at least one unique peptide. Data were statistically analyzed using Perseus v1.5.0.31 (part of the MaxQuant package). Intensities were normalized by the previously described intensity-based absolute quantification (iBAQ) method [38]. Average and standard deviations of duplicate samples of CB- and MCC-derived cellulosomes and triplicates of glucose-, alSG-, alCS-, and acCS-derived cellulosomes were analyzed.

\section{Results and discussion}

\section{Purification of different cellulosomes}

In order to investigate the influence of different carbon sources on the cellulosome composition and consequently on its activity, C. thermocellum strain DSM1313 was grown on cellobiose (CB), microcrystalline cellulose (MCC), alkaline-pretreated switchgrass (alSG), alkalinepretreated corn stover (alCS), and dilute acid-pretreated corn stover (acCS). The latter lignocellulosic biomasses are representative of industrially relevant feedstocks. Both alkaline- and dilute acid-based pre-treatments are well established and common in the bioethanol field, designed to enrich the cellulosic fraction, and to increase accessibility of hydrolytic enzymes. The chemical composition of the different lignocellulosic biomasses is shown in Table 1. In nature, C. thermocellum hydrolyzes the cellulose into soluble cellobiose units, which in turn are actively taken up by the bacterium and further hydrolyzed into glucose units by a cell-associated $\beta$-glucosidase. Soluble glucose can be directly utilized and used as the sole carbon source by some strains of $C$. thermocellum only after a prolonged adaptation period [13, 29, 30]. In this study, such an adaptation period was used to generate cellulosomes from glucose-based growth media. Production of cellulosome samples was

Table 1 Chemical composition of lignocellulosic biomasses used in this work

\begin{tabular}{llllll}
\hline & Abbreviation & Cellulose $^{\mathbf{a}}$ (\%) & Hemicellulose $^{\mathbf{a}}$ (\%) & Lignin $^{\mathbf{a}}$ (\%) & Non-ligno cellulose fraction $^{\mathbf{a}}$ (\%) \\
\hline Untreated switchgrass & SG & 37 & 28 & 18 & 17 \\
Untreated corn stover & CS & 36 & 27 & 20 & 17 \\
Alkaline-pretreated switchgrass (alSG) & alSG & 56 & 20 & 21 & 3 \\
Alkaline-pretreated corn stover (alCS) & alCS & 64 & 16 & 13 & 7 \\
Dilute acid-pretreated corn stover (acCS) & acCS & 60 & 5 & 30 & 5
\end{tabular}

a $\%$ dry matter 
accomplished in triplicate for each of the six different carbon sources. The soluble cell-free cellulosomes were purified and analyzed for their cellulolytic activity and subunit composition.

\section{Activity assays}

In order to calculate specific activities $[\mu \mathrm{M}$ reducing ends $\left.(\mu \mathrm{g} \text { protein })^{-1} \min ^{-1}\right]$, substrate degradation was quantified and total protein concentration in each sample was measured. MS analysis revealed that in addition to cellulosomal proteins, the "purified" high-molecular weight cellulosomal fraction also contained unrelated proteins, namely proteins without any known direct lignocellulolytic function (e.g., S-layer domain-containing proteins or flagellin domain-containing proteins). Consequently, the specific activity measured in a given sample would be biased by the presence of the unrelated proteins and would further lower the specific activity. In order to overcome this discrepancy, the relative content of cellulosomal proteins and non-cellulosomal enzymes in each sample was calculated using the MS data and used for calculations of the "true" specific activity.

Generally, the various isolated cellulosomes displayed varied specific activities on the different substrates, thus demonstrating the significant influence of the carbon source used in the growth media on the activity of the resulted cellulosome preparation (Fig. 1). One leading dogma assumes that cellulosomal subunit composition, generated from growth media supplemented with a specific carbon source, will lead to a superior activity
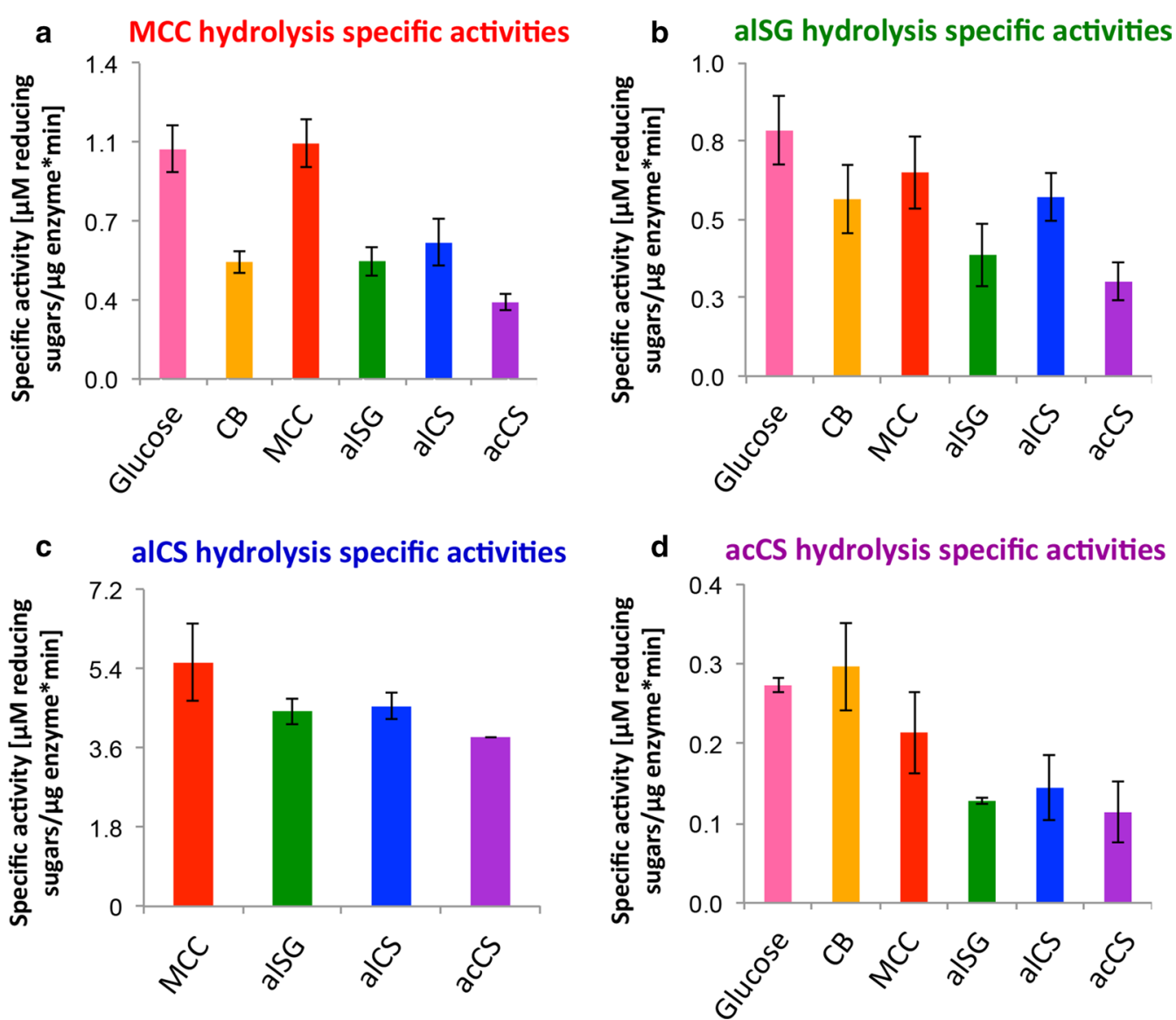

Fig. 1 Specific activities of the various cellulosome fractions: cellulosomes derived from glucose-, cellobiose (CB)-, microcrystalline cellulose (MCC)-, alkaline-pretreated switchgrass (alSG)-, alkaline-pretreated corn stover (alCS)-, and dilute acid-pretreated corn stover (acCS)-based growth media were applied on the different substrates and released soluble sugars were measured by the DNS method. The percent content of relevant enzymes (cellulosomal subunits and soluble carbohydrate-active enzymes) in each sample was calculated using MS, and specific activities were calculated $\left[\mu \mathrm{M}\right.$ reducing ends $\mu \mathrm{g}$ protein ${ }^{-1} \mathrm{~min}^{-1}$ ]. a Cellulosomes $(20 \mu \mathrm{g})$ were applied to $70 \mathrm{mg}$ MCC for $19 \mathrm{~h} ; \mathbf{b}$ cellulosomes $(60 \mu \mathrm{g})$ were applied to $50 \mathrm{mg}$ alSG for 16 h; c cellulosomes $(3 \mu \mathrm{g})$ were applied to $50 \mathrm{mg}$ alCS for $15 \mathrm{~h}$. d Cellulosomes $(50 \mu \mathrm{g}$ ) were applied to $50 \mathrm{mg}$ acCS for $18 \mathrm{~h}$. Cellulosomes and biomass dosages were determined in preliminary calibration assays in order to work in the near-linear range of the reaction (Additional file 2: Figure S2). All assays were performed at a final volume of $1 \mathrm{~mL}$, at $70^{\circ} \mathrm{C}$, with the addition of $0.33 \mathrm{mg} / \mathrm{mL}$ equivalent of Thermoanaerobacter brockii $\beta$-glucosidase (CgIT) in order to prevent feedback inhibition 
towards that specific carbon source. For example, cellulosome preparations, generated from bacteria grown on corn stover, would be assumed to display relatively high hydrolytic activity towards the same substrate, compared to cellulosome preparations generated from wheat straw or switchgrass. The results obtained in this study do not entirely support this dogma. Although the specific activity of MCC-derived cellulosomes in hydrolyzing MCC was indeed higher than those of the other cellulosome preparations (Fig. 1), no advantage was found for the lignocellulosic biomass-derived cellulosome preparations in the hydrolysis of the same type of biomass used to generate them. Moreover, cellulosomes derived from glucose-based substrates (i.e., MCC, CB, and glucose itself) exhibited higher specific activities towards acCS, compared to cellulosomes from bacteria grown on lignocellulosic biomass, including acCS itself. In the same manner, glucose- and MCC-derived cellulosome preparations revealed higher specific activities towards hydrolysis of alSG compared to the alSG-derived cellulosome. Interestingly, glucose- and MCC-derived cellulosomes showed similar specific activities on all tested biomasses, including MCC.

Previous proteomic and transcriptomic studies have suggested that understanding the relationship between a specific carbon source and the resultant cellulosomal subunit composition will enable selection of key potent enzymes for efficient hydrolysis of specific substrates important for industry [25, 28, 39]. Conversely, the results reported here suggest that glucose- and MCCderived cellulosomes are comparable or superior in their polysaccharase activity on all cellulosic substrates tested, to those obtained from cells grown on cellobiose or lignocellulosic substrates. Consequently, glucose- and MCCderived cellulosomes are better sources for determining optimal compositions of key enzymes than those derived from the other substrates tested. The finding that differential assembly processes and consequent cellulosome compositions do not necessarily display more efficient cellulosomes is supported by similar findings of hydrolyzing pretreated switchgrass by Clostridium clariflavum cellulosomes and partially by the hydrolysis of untreated wheat straw by Clostridium cellulolyticum cellulosomes $[40,41]$.

Several explanations can be suggested in order to explain these findings. For example, an optimized tailored cellulosome, assembled by the bacterium to fit a carbon source, is not necessarily the most active one. Alternatively, controlled hydrolysis rate, and the resultant controlled soluble sugar release, may serve to avoid competition and/or interact with surrounding satellite microorganisms [42]. In the same manner, uncontrolled biomass degradation can increase the release of inhibitors. Furthermore, the hydrolysis rate has to be synchronized with the cellobiose uptake rate, since high cellobiose concentrations can inhibit cellulosome activity [43]. Thus, it is likely that differential assembly of cellulosomal subunits in response to carbon source is designed to regulate the hydrolysis rate rather to achieve the highest rate of hydrolysis. Another possible explanation lies in the nature of the biomass used in the original bacterial cell culture. Pure cellulose chains, as well as soluble cellobiose or glucose, are not common in nature (except for wastes derived from human society). Even the lignocellulosic biomasses used in the present study have undergone pre-treatment steps, as required for the bioethanol production process. Therefore, the carbon sources used in this study are 'unnatural' substrates (i.e., not available to the bacteria in nature). The bacterial regulation apparatus, designed to respond to the natural carbon source in the environment, might be ineffective or even a source of interference for degradation of the 'unnatural' cellulosic substrates used here. The resultant cellulosome preparation would thus show no advantage in their hydrolysis [41].

\section{Mass spectrometry analysis}

The compositions of purified cellulosomes were analyzed by label-free LC-MS/MS. Peptide sequences from MS data were compared to the annotated protein database of C. thermocellum DSM1313 (NCBI, RefSeq NC017304.1) and further compared to the CAZY database for characterized carbohydrate-active enzymes (http://www. cazy.org/) [44]. Measured intensities were normalized using the intensity-based absolute quantification (iBAQ) method. Since mass spectrometry measurements depend not only on the concentration of each protein but also on its amino acid sequence, different proteins of the same concentration might reveal different total intensity measurements. The iBAQ method normalizes the results in a way that two different proteins with the same molar ratio will show similar iBAQ intensity, thus enabling internal comparison among samples (i.e., between different proteins in a given sample) [38].

\section{Scaffoldins}

Cellulosomes are heterogeneous sets of high-molecular weight multi-enzyme complexes composed of multidomain structural scaffoldins and several dozen catalytic subunits. The binding of the catalytic subunits is mediated by the high-affinity noncovalent interactions between the multiple scaffoldin-borne cohesin modules and a dockerin module located in each catalytic subunit. The primary scaffoldin in C. thermocellum, CipA (Clo1313_0627), herein termed as ScaA (Fig. 2) according to Bras et al. [45], serves as a binding platform for the 


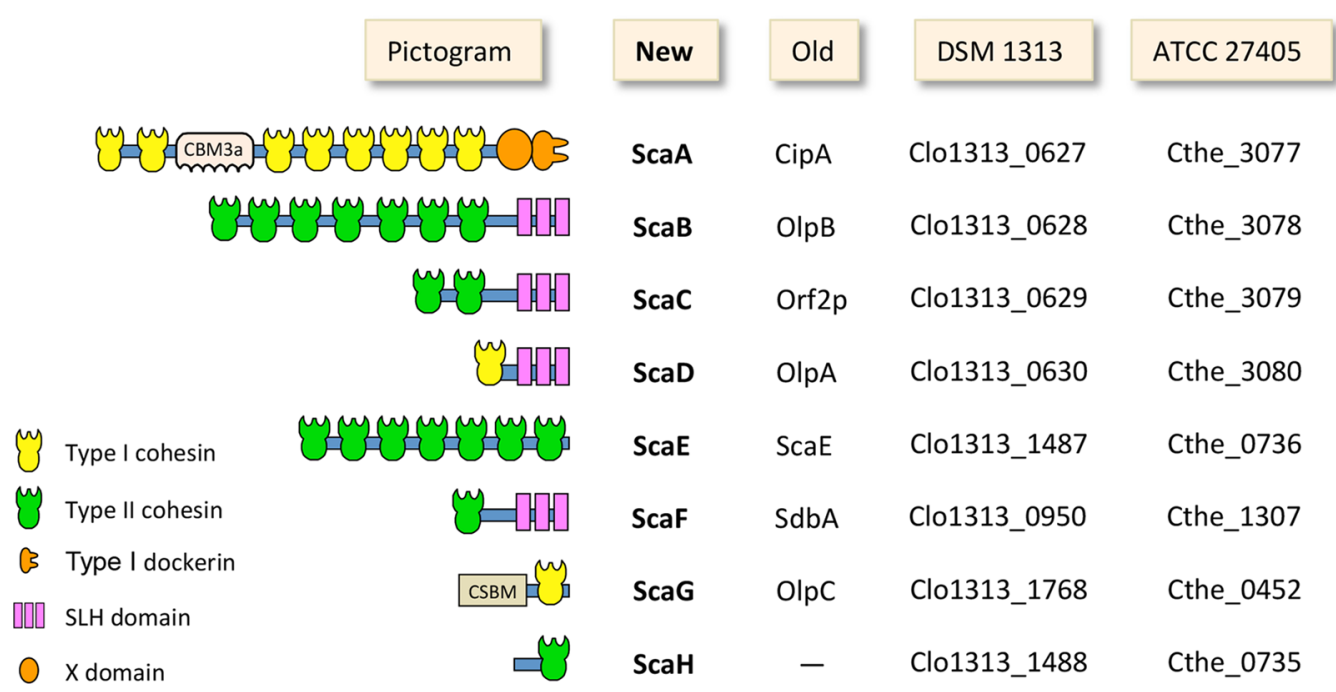

Fig. 2 Schematic diagram of the eight C. thermocellum DSM1313 scaffoldins. The genome of C. thermocellum DSM1313 (RefSeq NC017304.1) was screened for cohesin-containing proteins, and annotated by NCBI annotation software. New (as reported in Bras et al. [45]) and old terminologies are shown for the scaffoldins, together with their gene loci in strain DSM 1313 and their equivalents in the ATCC 27405 strain. CBM, carbohydratebinding module; SLH, surface-layer homology; CSBM, cell-surface binding module. The numbers of cohesins in ScaA and ScaB (8 and 7, respectively) shown in the figure are according to the recent report of Hong et al. [49]

catalytic subunits via type I cohesin-dockerin interactions. In addition, $C$. thermocellum cellulosomes can be assembled into more complex cellulosomal suprastructures (polycellulosome complexes) via secondary scaffoldins. This type of assembly is mediated by the interaction of a type II dockerin module (located at the $\mathrm{C}$ terminus of the scaffoldin) with type II cohesins located in the secondary scaffoldin. Those secondary scaffoldins might be either cell-associated anchoring scaffoldins (mediating attachment of cellulosomes to the bacterial cell wall via their S-layer homology [SLH] domain $[18,19])$ or soluble cell-free scaffoldins (lacking the SLH domain). Secondary scaffoldins, which bear several type II cohesins, can bind an equivalent number of primary scaffoldins and thus can assemble poly-cellulosomal complexes of different size, architecture, and content. The organization of the catalytic subunits on structural scaffoldins create a proximity effect that enhances synergy among neighboring enzymes $[20,46]$.

In order to analyze the structure of the different cellulosome samples, the genome of $C$. thermocellum DSM1313 (NC017304.1) [47] was screened for cohesin-bearing proteins. A schematic diagram of all $C$. thermocellum DSM1313 scaffoldins is shown in Fig. 2. Previously identified scaffoldins are now coined herein according to new terminology as reported in Bras et al. [45]. The scaffoldins of strain DSM1313 are similar in architecture and content to those of strain ATCC 27405 [48], with two noticeable differences: (A) according to the available genome sequence, DSM1313 ScaA contains six type I cohesin domains while ATCC 27405 ScaA (CipA) contains nine type I cohesin modules, and (B) the DSM1313 secondary scaffoldin $\mathrm{ScaB}$ contains four type II cohesin modules, whereas ATCC 27405 ScaB (OlpB) contains seven type II cohesin modules. While those discrepancies arise from sequence annotation, it is relevant to note that Hong et al. [49] have claimed that the genomic sequencing of the cipA and olpB genes in the DSM1313 strain was incorrect. Based on PCR reaction studies, these authors claimed that $C$. thermocellum DSM1313 ScaA contains eight cohesins (one less than that reported for C. thermocellum ATCC 27405 [50]) and ScaB contains seven cohesins (similar to that of $C$. thermocellum ATCC $27405 \mathrm{OlpB})$. In the present work, we have accepted the latter claims and used a value of eight type I cohesins for ScaA and seven type II cohesins for ScaB.

MS analysis revealed the presence of all eight known scaffoldins in all cellulosome samples, albeit some (i.e., $\mathrm{ScaH}$ and $\mathrm{ScaE}$ in some samples) were present only in relatively minor amounts.

\section{Secondary scaffoldins}

In order to shed light on the polycellulosomes suprastructures, the relative proportion of each secondary scaffoldin, derived from cells grown on each substrate, was assessed (Fig. 3). The different cellulosome samples exhibited differences in distribution of the secondary scaffoldins.

The most abundant secondary scaffoldin in most of the tested cellulosomal samples (i.e., CB-, MCC-, alSG-, and 


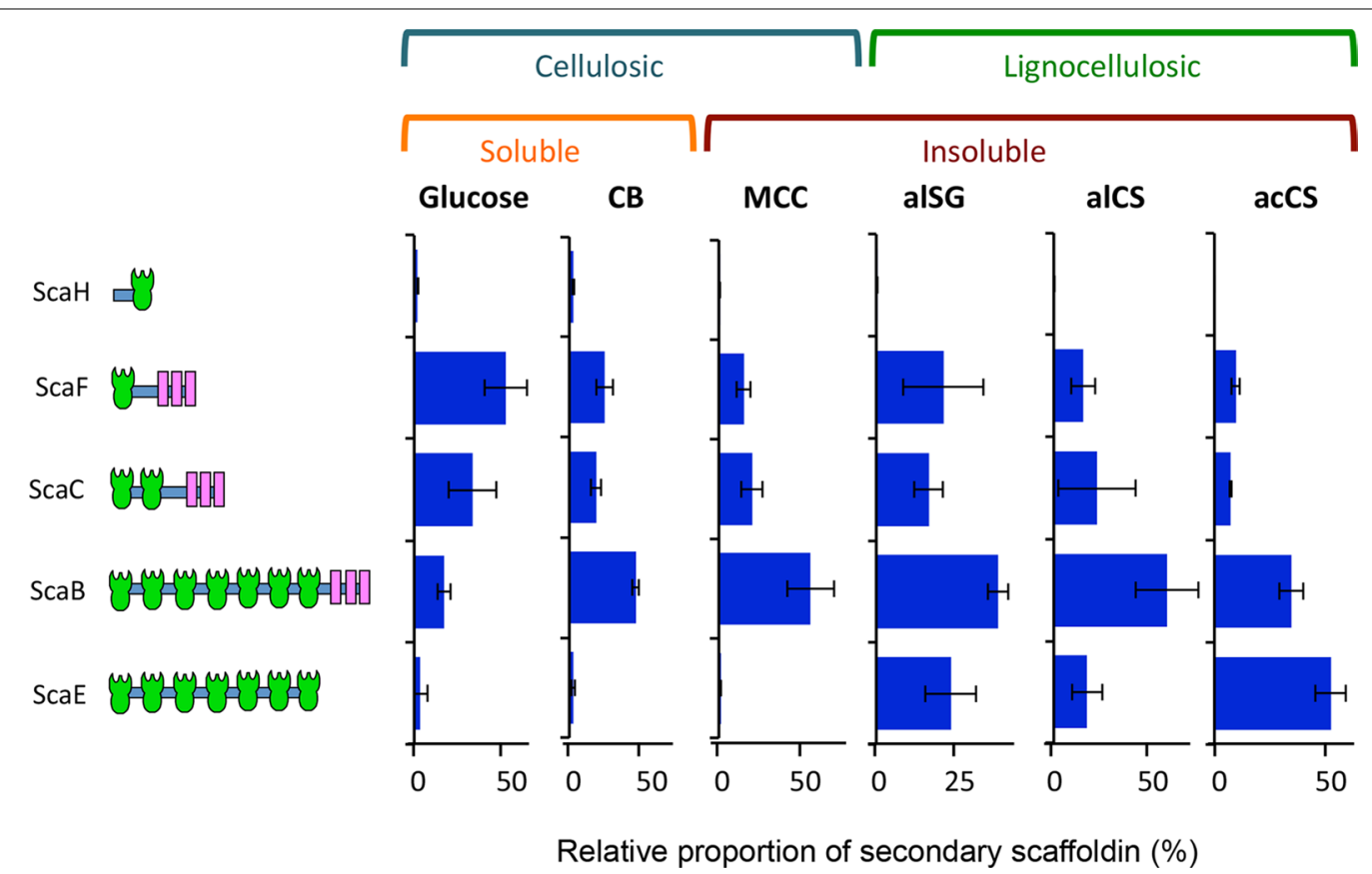

Fig. 3 Differential distribution of secondary type II cohesin-containing scaffoldins. iBAQ intensities of all secondary scaffoldins in each sample were summed up, and the relative proportions of each secondary scaffoldin in each sample was calculated. The carbon source (see legend to Fig. 1 for definitions) used for the respective cellulosome production is shown in the graph

alCS-derived cellulosomes) was ScaB. In contrast, the most abundant secondary scaffoldin for acCS-derived cellulosomes was ScaE. Both ScaB and ScaE (containing seven cohesin models, respectively) enable the formation of large polycellulosome superstructures. Conversely, the most abundant secondary scaffoldin in the glucosederived cellulosomes was ScaF (formerly SdbA), containing only one cohesin module. The combined amount of both ScaB and ScaE in the glucose-derived samples was only $19 \%$ (compared to $51-83 \%$ in the other samples). These results suggest the formation of significantly smaller cellulosomal complexes in the glucose-derived cellulosomes. It was therefore of interest to consider whether the multiple polycellulosome suprastructures assembled by the various secondary scaffoldins would directly influence their activity on (ligno) cellulosic substrates. For example, cellulosome architecture could possibly increase the synergistic effect by assembling several individual cellulosomes into a higher order structure, each of which would bear a different composition of catalytic subunits. In addition, the size of the polycellulosome complex may influence its accessibility to the crystalline cellulosic regions of the substrate [51]. However, no connection was observed in the present study between the distribution of secondary scaffoldins and the activity of the various cellulosome preparations. Intriguingly, glucose- and MCC-derived samples revealed similar levels of activity (Fig. 1), despite of the differences in the distribution of their secondary scaffoldins. In addition, CB- and MCC-derived cellulosomes exhibited similar patterns of secondary scaffoldins but significantly different specific activities when assayed for hydrolysis of MCC. These results indicate that the distribution of secondary scaffoldin per se does not significantly influence specific activity. Our results correspond to previously described reports, demonstrating that secondary scaffoldins exhibit only a minor effect on the hydrolysis of cellulosic substrates compared to the critical effect of ScaA [49, 52-55].

ScaE contains seven type II cohesins but lacks an SLH domain. The relative proportion of ScaE was higher (one order of magnitude) in lignocellulosic substrate-derived cellulosomes (i.e., alSG, alCS, and acCS) compared to that of cellulosomes derived from cells grown on pure homogeneous cellulose and its degradation products (i.e., MCC, CB, and glucose). ScaE was found to mediate the assembly of large polycellulosome complexes [52]. Those complexes were termed long-range, cell-free cellulosomes due to the lack of SLH or any other known module or sequence that would facilitate their binding to the C. thermocellum cell wall [52]. It was suggested that such "cell-free cellulosomes" can diffuse away from the cell and degrade polysaccharide substrates remotely from the bacterial cell [52]. It was further suggested that such a system can accommodate and target catalytic subunits 
involved in the hydrolysis of "non-cellulosic" [25] (i.e., hemicellulosic) polysaccharides via the CBM domain of the scaffoldin. In this context, the hemicellulase subunits would thus expose the cellulose microfibrils of complex lignocellulosic substrates, thereby enabling its sequential hydrolysis by the cell-surface cellulosomes. Interestingly, our results demonstrate relatively high portions of ScaE when C. thermocellum DSM1313 was grown on lignocellulosic substrates (where exposure of cellulose fibrils is necessary) and relatively low portions of ScaE when C. thermocellum DSM1313 was grown on pure cellulose or its degradation products (where such exposure of the microfibrils is not required).

Another "cell free" secondary scaffoldin produced by this bacterium is $\mathrm{ScaH}$ (that contains only a single type II cohesin without an SLH domain). This secondary scaffoldin was the least abundant in all samples. Nevertheless, the relative portion of $\mathrm{ScaH}$ in cellulosomes derived from soluble substrates (i.e., CB and glucose) was one order of magnitude higher compared to those of cellulosomes derived from the lignocellulosic substrates (i.e., alSG, alCS, and acCS) and $~ 2.5$-fold higher than that of MCCderived cellulosome.

\section{Primary scaffoldins}

Among all structural proteins, the relative proportion of primary scaffoldins (type I cohesin-containing proteins) was larger than that of the secondary scaffoldins in all samples, accounting for $58-63 \%$ in the glucose-, CB-, and MCC-derived cellulosomes, and $76-80 \%$ for the lignocellulose-derived cellulosomes (Table 2).

Figure 4 summarizes the distribution of the primary scaffoldins. ScaA, by far, comprised the great majority of the primary scaffoldins, accounting for 67\% (in CB-derived cellulosomes) up to $98 \%$ (in alSG-derived cellulosomes), followed by ScaD, and ScaG. The relative proportion of ScaD and ScaG (single type I cohesin) was significantly lower in the insoluble substrate-derived cellulosomes $(7.7,2.3,5.1$, and $6.5 \%$ for MCC-, alSG-, alCS-, and acCS-derived cellulosomes, respectively) compared to that of the glucose- and cellobiose-derived

Table 2 Relative proportion of primary and secondary scaffoldins in the different samples

\begin{tabular}{lll}
\hline Carbon source & Primary scaffodins (\%) & Secondary scaffoldins (\%) \\
\hline Glucose & $60 \pm 3$ & $40 \pm 3$ \\
CB & $63 \pm 1$ & $37 \pm 1$ \\
MCC & $58 \pm 6$ & $42 \pm 6$ \\
alSG & $76 \pm 2$ & $24 \pm 2$ \\
alCS & $78 \pm 6$ & $22 \pm 6$ \\
acCS & $80 \pm 2$ & $20 \pm 2$ \\
\hline
\end{tabular}

cellulosomes (18.3 and 33\% for glucose- and CB-derived cellulosomes, respectively). These results correlate with the measured intensities of Cthe_0452 (ScaG homolog) in the ATCC 27405 CB-derived cellulosomes versus those derived from insoluble substrates [25].

\section{Occupancy of type II cohesins}

ScaA is the only primary scaffoldin that contains a type II dockerin that can bind to the type II cohesins of secondary scaffoldins. Comparison of the amount of ScaA to that of the available type II cohesins can also provide insight into the suprastructure of the different cellulosome samples. In order to calculate the type II dockerin-to-cohesin ratio, the relative portions of the secondary scaffoldins were multiplied by the number of their cohesins, and the ScaA/type II cohesin ratio was calculated. The ratio for CB- and MCC-derived cellulosomes was $0.26 \pm 0.0$ and $0.27 \pm 0.07$, respectively. Significantly higher ratios were found for the lignocellulosic biomass-derived cellulosomes $(0.61 \pm 0.03,0.65 \pm 0.2$, and $0.63 \pm 0.09$ for alSG-, alCS-, and acCS-derived cellulosomes, respectively), thus indicating a higher degree of occupancy and complexity in the lignocellulosic biomass-derived cellulosomes. Interestingly, cellulosomes that exhibited higher occupancies for type II cohesins (i.e., lignocellulosic substrate-derived cellulosomes) generally showed relatively lower levels of specific activities (Fig. 1). Surprisingly, the ratio of glucose-derived cellulosomes was $0.51 \pm 0.09$, similar to those of the lignocellulosic substrate-derived cellulosomes. Yet, the glucose-derived cellulosomes exhibited relatively high specific activity values. This result may be related to the distribution of secondary scaffoldins in the glucose-derived cellulosomes, which shows a majority of the monovalent scaffoldin ScaF, as opposed to the other types of cellulosome. Thus, in this case, the degree of occupancy may only have a negligible influence on activity. Incomplete occupancy of type II cohesins was previously reported for C. thermocellum ATCC 27405 cellulosomes, with even lower occupancy levels at the proteome [25] and transcriptome levels [56].

\section{Cellulosomal subunits}

In order to analyze subunit composition of the different cellulosome samples, the $C$. thermocellum DSM1313 genome was screened for type I dockerin-containing proteins. Seventy-five hypothetical cellulosomal subunits were thus revealed. Altogether, the proteomic study revealed 67 different dockerin-containing proteins in the cellulosome samples. For comparison among the different cellulosome samples, iBAQ intensities of cellulosomal subunits of a given sample were normalized with that of the primary scaffoldin ScaA (CipA) from the same sample, thus creating a relative abundance index. The 


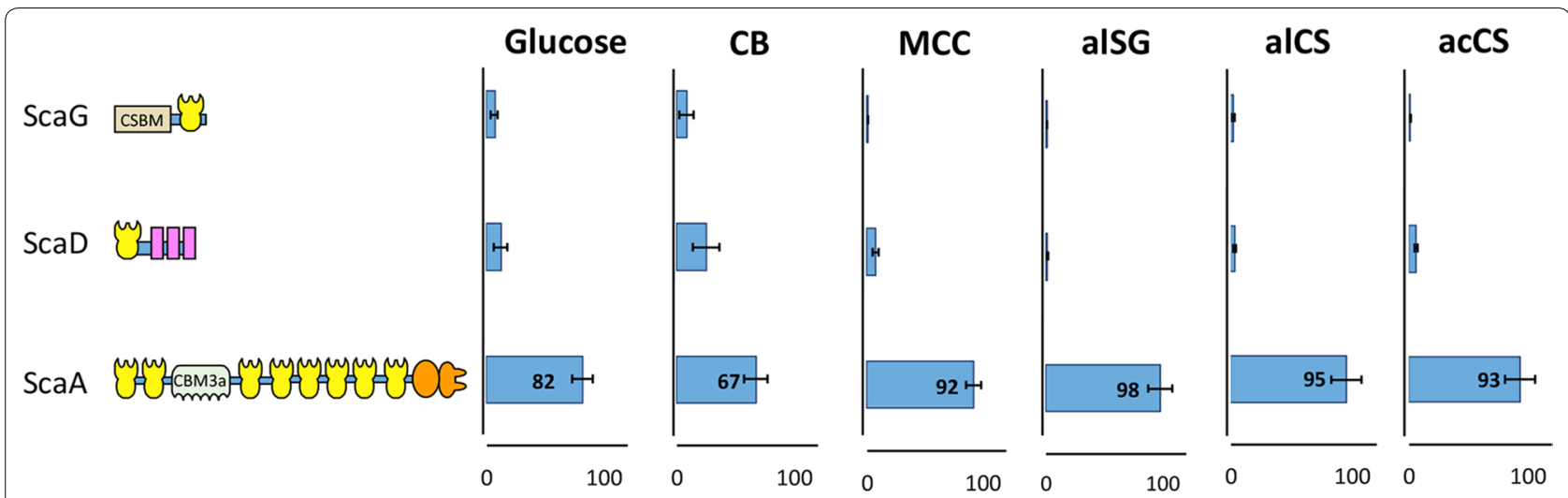

Fig. 4 Differential distribution of primary (type I cohesin-containing) scaffoldins. iBAQ intensities of the primary scaffoldins in each sample were summed up, and the relative proportions of each primary scaffoldin in each sample was calculated. The carbon source (see legend to Fig. 1 for definitions) used for the respective cellulosome production is shown in the graph

use of ScaA as an internal standard provides information regarding the composition of the cellulosome subpopulations within each sample (as described in previous proteomic studies $[25,26])$. The values obtained reveal differences between samples, by comparing the relative abundance of the individual subunits. It is important to emphasize that ScaA is a glycosylated protein [57-60]. Glycosylation changes the molecular weight of a peptide, which interferes with its identification by the LC-MS/ MS. Since iBAQ normalization takes into account the number of theoretical peptides, the iBAQ intensity of ScaA is probably underestimated. Nevertheless, the relative abundance index enables comparison within samples, and, assuming identical glycosylation of ScaA in all samples, among samples as well [25].

The table in Fig. 5 summarizes the relative abundance values of the cellulosomal subunits detected in the different samples. The twenty most abundant enzymes are marked and rated using the color scale shown in the table. The five most abundant proteins accounted for at least $50 \%$ of total cellulosomal subunits in each sample, with a higher percentage (60-64\%) in the lignocellulosic biomass-derived cellulosomes, compared to those (50-56\%) in the glucose-, cellobiose-, and MCC-derived cellulosomes. The most abundant subunits in all samples included exoglucanases Cel48S (Clo1313_2747) and Cel9K (Clo1313_1809), and endoglucanases Cel9Q (Clo1313_1603), Cel9R (Clo1313_16590), and Cel5G (Clo1313_0413), indicating their importance in biomass degradation. Out of the 20 most abundant catalytic subunits, 12 were common among all samples. The detected cellulosomal subunits were analyzed for their functional class distribution (Fig. 6; Additional file 3: Table S1). The cellulase (endo- and exoglucanase) portion was about $76-78 \%$ of the total cellulosomal subunits in all samples, except for the CB-derived samples, in which the cellulase portion was somewhat lower (71\%). The endoglucanaseto-exoglucanase ratio was found to be higher in glucose-, cellobiose-, and MCC-derived cellulosomes (1.4, 2, and 1.65 , respectively), compared to that of the lignocellulosic biomass-derived cellulosomes (0.71, 0.9 and 0.64 for alSG-, alCS-, and acCS-derived cellulosomes, respectively). Since glucose and MCC-derived cellulosomes showed higher specific activity, we may hypnotize that an endo-to-exo ratio of $\sim 1.5$ is recommended for assembly of cellulolytic cocktails based on C. thermocellum enzymes.

\section{Exoglucanases}

Excluding CB-derived cellulosomes, all samples revealed a similar pattern of exoglucanases, in which the relative abundance value of Cel48S was the highest, cell9K showed the second highest, followed by CbhA, and finally Cel5O with the lowest level of abundance. In the CB-derived cellulosomes, Cel9K showed the highest relative abundance among the four exoglucanases. Cel48S and CbhA showed lower levels, but the differences were not statistically significant. Similar trends of lower Cel48S abundance in the CB-derived cellulosomes compared to that of MCC-derived cellulosomes was previously reported for $C$. thermocellum ATCC 27405, both at the transcriptome and protein levels $[21,25,61,62]$, thus confirming our present data. The lignocellulosic biomass-derived cellulosomes revealed modest decreases in the relative abundance of Cel48S, compared to that of the MCC-derived cellulosomes. Only glucose-derived cellulosomes revealed a similar level of relative abundance of Cel48S to those of MCC-derived cellulosomes.

Cel9K showed similarly, higher relative abundance in the MCC- and glucose-derived cellulosomes, and the 


\begin{tabular}{|c|c|c|c|c|c|c|c|c|}
\hline & & & Glucose & $C B$ & MCC & SG-AL & CS-AL & $\mathrm{CSAC}$ \\
\hline Clo1313_2747 & Cel48S & GH48 & $4.04 E+00 \pm 0.38$ & $1.62 E+00 \pm 0.25$ & $0 E+00 \pm 0.15$ & $2.88 E+00 \pm 0.50$ & $3.52 E+00 \pm 0.30$ & $3.04 E+00 \pm 0.54$ \\
\hline Clo1313_1809 & Cel9K & CBM4,GH9 & $2.45 E+00 \pm 0.39$ & $1.70 E+00 \pm 0.69$ & $2.83 \mathrm{E}+00 \pm 0.39$ & $2.33 E+00 \pm 0.45$ & $2.14 E+00 \pm 0.46$ & $1.91 E+00 \pm 0.44$ \\
\hline Clo1313_1603 & Cel9a & GH9,CBM3 & $2.09 E+00 \pm 0.38$ & $1.25 E+00 \pm 0.34$ & $2.66 \mathrm{E}+00 \pm 0.06$ & $6.65 \mathrm{E}-01 \pm 0.05$ & $1.23 \mathrm{E}+00 \pm 0.30$ & $5.29 \mathrm{E}-01 \pm 0.06$ \\
\hline Clo1313_1659 & Cel9R & GH9,CBM3 & $7.55 \mathrm{E}-01 \pm 0.13$ & $1.32 E+00 \pm 0.17$ & $1.69 \mathrm{E}+00 \pm 0.32$ & $4.59 \mathrm{E}-01 \pm 0.03$ & $6.93 \mathrm{E}-01 \pm 0.15$ & $4.57 \mathrm{E}-01 \pm 0.09$ \\
\hline Clo1313_0413 & Cel5G & GH5 & $1.67 \mathrm{E}+00 \pm 0.05$ & $2.24 E+00 \pm 0.32$ & $1.56 \mathrm{E}+00 \pm 0.33$ & $7.70 \mathrm{E}-01 \pm 0.08$ & $1.02 E+00 \pm 0.10$ & $5.77 \mathrm{E}-01 \pm 0.08$ \\
\hline Clo1313_1477 & Celgw & GH9,CBM3 & $3.79 \mathrm{E}-01 \pm 0.13$ & $7.28 E-01 \pm 0.13$ & $1.48 E+00 \pm 0.08$ & $1.26 \mathrm{E}-01 \pm 0.02$ & $2.32 E-01 \pm 0.06$ & $1.46 E-01 \pm 0.03$ \\
\hline Clo1313_1398 & & GH5,CBM32 & $7.76 \mathrm{E}-02 \pm 0.05$ & $2.59 \mathrm{E}-02 \pm 0.02$ & $7.91 \mathrm{E}-01 \pm 0.07$ & $7.33 \mathrm{E}-02 \pm 0.02$ & $2.24 \mathrm{E}-01 \pm 0.04$ & $2.03 E-01 \pm 0.04$ \\
\hline Clo1313_3023 & Celgu & GH9,СBM3,СBM3 & $1.04 \mathrm{E}+00 \pm 0.25$ & $2.77 E-01 \pm 0.12$ & $5.93 E-01 \pm 0.01$ & $2.85 \mathrm{E}-01 \pm 0.0$ & $4.12 E-01 \pm 0.10$ & $2.64 \mathrm{E}-01 \pm 0$ \\
\hline Clo1313_0349 & Cel9v & GH9,СВM3,СВM3 & $2.47 \mathrm{E}-01 \pm 0.09$ & $4.34 \mathrm{E}-01 \pm 0.15$ & $5.91 E-01 \pm 0.10$ & $2.73 \mathrm{E}-01 \pm 0.01$ & $2.54 \mathrm{E}-01 \pm 0.05$ & $1.23 \mathrm{E}-01 \pm 0.00$ \\
\hline Clo1313_0400 & Cel9T & GH9 & $4.84 \mathrm{E}-01 \pm 0.04$ & $2.35 \mathrm{E}-01 \pm 0.03$ & $5.56 \mathrm{E}-01 \pm 0.00$ & $1.66 \mathrm{E}-01 \pm 0.02$ & $3.58 \mathrm{E}-01 \pm 0.06$ & $2.14 \mathrm{E}-01 \pm 0.03$ \\
\hline Clo1313_1701 & Cel5B & GH5 & $1.19 E+00 \pm 0.32$ & $7.83 \mathrm{E}-01 \pm 0.01$ & $5.31 E-01 \pm 0.04$ & $2.17 \mathrm{E}-01 \pm 0.04$ & $3.94 \mathrm{E}-01 \pm 0.07$ & $1.49 \mathrm{E}-01 \pm 0.03$ \\
\hline Clo1313_0177 & & CBM22,GH10 & $2.17 \mathrm{E}-01 \pm 0.05$ & $1.37 \mathrm{E}-01 \pm 0.03$ & $5.09 E-01 \pm 0.27$ & $1.67 E-01 \pm 0.11$ & $2.27 \mathrm{E}-01 \pm 0.22$ & $8.41 E-02 \pm 0.07$ \\
\hline Clo1313_1604 & Cel 9/44 J & $\mathrm{CBM} 30, \mathrm{GH} 9, \mathrm{GH} 44, \mathrm{C}$ & $6.08 \mathrm{E}-01 \pm 0.13$ & $2.56 E-01 \pm 0.06$ & $4.86 \mathrm{E}-01 \pm 0.07$ & $2.81 E-01 \pm 0.04$ & $2.95 \mathrm{E}-01 \pm 0.09$ & $1.79 \mathrm{E}-01 \pm 0.03$ \\
\hline Clo1313_1808 & $\mathrm{cbhA}$ & CBM4,GH9, СBM3 & $8.66 \mathrm{E}-01 \pm 0.11$ & $9.32 \mathrm{E}-01 \pm 0.35$ & $4.02 E-01 \pm 0.06$ & $2.90 \mathrm{E}-01 \pm 0.02$ & $6.82 \mathrm{E}-01 \pm 0.18$ & $3.30 \mathrm{E}-01 \pm 0.08$ \\
\hline Clo1313_2189 & Celon & GH9,СBM3 & $3.31 E-02 \pm 0.01$ & $1.39 \mathrm{E}-01 \pm 0.03$ & $3.87 \mathrm{E}-01 \pm 0.04$ & $1.04 \mathrm{E}-01 \pm 0.04$ & $1.76 E-01 \pm 0.03$ & $1.17 \mathrm{E}-01 \pm$ \\
\hline Clo1313_2635 & & СЕ1,СВM6,GH10 & $3.12 E-01 \pm 0.06$ & $1.42 \mathrm{E}-01 \pm 0.03$ & $3.65 E-01 \pm 0.02$ & $6.29 \mathrm{E}-02 \pm 0.01$ & $1.13 \mathrm{E}-01 \pm 0.01$ & $6.34 \mathrm{E}-02 \pm 0.00$ \\
\hline Clo1313_1955 & Celgp & GH9 & $4.52 \mathrm{E}-01 \pm 0.05$ & $3.04 E-01 \pm 0.08$ & $3.31 E-01 \pm 0.02$ & $6.90 \mathrm{E}-02 \pm 0.01$ & $1.50 \mathrm{E}-01 \pm 0.01$ & $1.15 E-01 \pm 0.02$ \\
\hline Clo1313_0399 & & CBM35,GH26 & $3.88 \mathrm{E}-02 \pm 0.01$ & $3.52 \mathrm{E}-02 \pm 0.00$ & $3.28 \mathrm{E}-01 \pm 0.02$ & $1.07 E-01 \pm 0.03$ & $1.34 \mathrm{E}-01 \pm 0.02$ & $8.28 \mathrm{E}-02 \pm 0.01$ \\
\hline Clo1313_1960 & Cel8A & GH8 & $5.83 \mathrm{E}-01 \pm 0.10$ & $3.57 E-01 \pm 0.02$ & $3.07 E-01 \pm 0.02$ & $1.01 E-01 \pm 0.00$ & $1.58 E-01 \pm 0.02$ & $8.11 \mathrm{E}-02 \pm 0.02$ \\
\hline Clo1313_0350 & & GH9,СвM3 & $1.22 \mathrm{E}-01 \pm 0.03$ & $3.77 E-01 \pm 0.19$ & $2.97 E-01 \pm 0.00$ & $1.56 \mathrm{E}-01 \pm 0.02$ & $1.61 E-01 \pm 0.03$ & $7.33 \mathrm{E}-02 \pm 0$. \\
\hline Clo1313_1788 & & GH9, СBM3 & $6.06 E-01 \pm 0.03$ & $3.64 \mathrm{E}-01 \pm 0.18$ & $2.87 \mathrm{E}-01 \pm 0.03$ & $4.07 E-01 \pm 0.01$ & $3.89 \mathrm{E}-01 \pm 0.09$ & $1.73 \mathrm{E}-01 \pm 0.04$ \\
\hline Clo1313_2530 & kync & СBM22,GH10 & $5.05 E-01 \pm 0.08$ & $8.75 E-01 \pm 0.05$ & $2.70 \mathrm{E}-01 \pm 0.04$ & $3.13 E-01 \pm 0.04$ & $2.93 \mathrm{E}-01 \pm 0.01$ & $2.11 E-01 \pm$ \\
\hline Clo1313_1694 & CelgF & GH9,СBM3 & $2.97 E-01 \pm 0.12$ & $1.96 E-01 \pm 0.05$ & $1.93 \mathrm{E}-01 \pm 0.02$ & $2.06 \mathrm{E}-01 \pm 0.07$ & $1.35 \mathrm{E}-01 \pm 0.06$ & $2.77 \mathrm{E}-01 \pm 0.02$ \\
\hline Clo1313_2693 & & & $3.57 \mathrm{E}-01 \pm 0.09$ & $3.24 E-01 \pm 0.09$ & $1.84 \mathrm{E}-01 \pm 0.06$ & $1.03 \mathrm{E}-01 \pm 0.01$ & $1.12 \mathrm{E}-01 \pm 0.02$ & $8.35 E-02 \pm 0.01$ \\
\hline Clo1313_0521 & In11A & GH11,CBM6,CE4 & $6.91 E-02 \pm 0.04$ & $1.42 E-01 \pm 0.01$ & $1.76 \mathrm{E}-01 \pm 0.04$ & $1.32 E-01 \pm 0.05$ & $1.38 \mathrm{E}-01 \pm 0.03$ & $8.56-02 \pm 0.04$ \\
\hline Clo1313_1396 & Cel9D & GH9 & $1.77 \mathrm{E}-01 \pm 0.05$ & $1.63 \mathrm{E}-01 \pm 0.09$ & $1.54 \mathrm{E}-01 \pm 0.00$ & $3.97 \mathrm{E}-02 \pm 0.01$ & $6.69 \mathrm{E}-02 \pm 0.00$ & $6.45 E-02 \pm 0$ \\
\hline Clo1313_1816 & CelsL & GH5 & $1.82 \mathrm{E}-01 \pm 0.05$ & $4.56 \mathrm{E}-02 \pm 0.00$ & $1.52 \mathrm{E}-01 \pm 0.01$ & $2.37 \mathrm{E}-02 \pm 0.01$ & $5.22 \mathrm{E}-02 \pm 0.01$ & $3.18 \mathrm{E}-02 \pm 0.01$ \\
\hline \begin{tabular}{|ll} 
Clo1313_1305 \\
\end{tabular} & & СBM22,GH10,CB & $2.36 \mathrm{E}-01 \pm 0.03$ & $1.82 \mathrm{E}-01 \pm 0.00$ & $1.09 \mathrm{E}-01 \pm 0.01$ & $1.00 \mathrm{E}-02 \pm 0.00$ & $2.33 E-02 \pm 0.01$ & $1.75 \mathrm{E}-02 \pm 0.01$ \\
\hline Clo1313_0851 & h74A & GH74 & $1.40 \mathrm{E}-01 \pm 0.06$ & $8.91 \mathrm{E}-02 \pm 0.03$ & $8.65 \mathrm{E}-02 \pm 0.02$ & $1.05 \mathrm{E}-01 \pm 0.03$ & $2.05 \mathrm{E}-01 \pm 0.01$ & $6.65 \mathrm{E}-02 \pm 0.0$ \\
\hline Clo1313_1587 & & & $6.35 E-02 \pm 0.01$ & $2.13 \mathrm{E}-01 \pm 0.04$ & $4.60 \mathrm{E}-02 \pm 0.01$ & $3.52 \mathrm{E}-02 \pm 0.01$ & $6.56 \mathrm{E}-02 \pm 0.01$ & $1.99 \mathrm{E}-02 \pm 0.0$ \\
\hline Clo1313_2805 & Cel50 & CBM3,GH5 & $4.25 \mathrm{E}-02 \pm 0.01$ & $1.10 \mathrm{E}-01 \pm 0.04$ & $4.39 \mathrm{E}-02 \pm 0.00$ & $2.55 \mathrm{E}-02 \pm 0.00$ & $3.86 \mathrm{E}-02 \pm 0.01$ & $2.08 \mathrm{E}-02 \pm 0$ \\
\hline Clo1313_2043 & & & $1.52 \mathrm{E}-03 \pm 0.00$ & $8.89 \mathrm{E}-03 \pm 0.00$ & $3.15 \mathrm{E}-02 \pm 0.02$ & $1.68 \mathrm{E}-02 \pm 0.00$ & $1.49 \mathrm{E}-02 \pm 0.00$ & $1.22 \mathrm{E}-02 \pm 0.00$ \\
\hline Clo131 & & & $1.87 \mathrm{E}-02 \pm 0.01$ & $6.94 \mathrm{E}-03 \pm 0.00$ & $3.15 \mathrm{E}-02 \pm 0.01$ & $4.30 \mathrm{E}-03 \pm$ & $2.46 \mathrm{E}-03 \pm 0.00$ & $2.05 \mathrm{E}-04 \pm 0$. \\
\hline Clo1313_1425 & s & GH5,CE2 & $1.42 \mathrm{E}-02 \pm 0.01$ & $5.37 \mathrm{E}-03 \pm 0.00$ & $2.38 \mathrm{E}-02 \pm 0.00$ & $1.73 \mathrm{E}-02 \pm 0.01$ & $1.51 \mathrm{E}-02 \pm 0.01$ & $2.26 \mathrm{E}-02 \pm 0$ \\
\hline Clo1313_0849 & & GH53 & $1.03 \mathrm{E}-02 \pm 0.00$ & $1.24 \mathrm{E}-02 \pm 0.00$ & $2.36 \mathrm{E}-02 \pm 0.00$ & $8.46 \mathrm{E}-03 \pm 0.00$ & $1.01 \mathrm{E}-02 \pm 0.00$ & $4.41 \mathrm{E}-03 \pm 0.00$ \\
\hline Clo13. & & GH43,CBM13 & $1.58 \mathrm{E}-02 \pm 0.01$ & $3.25 \mathrm{E}-02 \pm 0.00$ & $2.29 \mathrm{E}-02 \pm 0.02$ & $7.14 \mathrm{E}-04 \pm 0.00$ & $7.00 \mathrm{E}-04 \pm 0.00$ & $2.37 \mathrm{E}-03 \pm 0.00$ \\
\hline Clo1313_2202 & & СBM35,GH26 & $1.51 \mathrm{E}-01 \pm 0.05$ & $2.41 \mathrm{E}-02 \pm 0.00$ & $2.22 \mathrm{E}-02 \pm 0.01$ & $3.79 \mathrm{E}-02 \pm 0.01$ & $9.20 \mathrm{E}-02 \pm 0.02$ & $2.56 \mathrm{E}-02 \pm 0.01$ \\
\hline Clo1313_2856 & & GH5, СBM6,CB & $6.01 \mathrm{E}-02 \pm 0.01$ & $1.30 \mathrm{E}-01 \pm 0.03$ & $1.95 \mathrm{E}-02 \pm 0.00$ & $1.46 \mathrm{E}-02 \pm 0.00$ & $1.92 \mathrm{E}-02 \pm 0.00$ & $3.08 \mathrm{E}-02 \pm 0$ \\
\hline Clo1313_0522 & & GH11,CBM6 & $2.62 \mathrm{E}-03 \pm 0.00$ & $5.65 \mathrm{E}-03 \pm 0.00$ & $1.87 \mathrm{E}-02 \pm 0.00$ & $5.79 \mathrm{E}-03 \pm 0.00$ & $6.88 \mathrm{E}-03 \pm 0.00$ & $3.21 \mathrm{E}-03 \pm 0.00$ \\
\hline Clo13 & & CEnc & $3.91 \mathrm{E}-03 \pm 0.00$ & $3 \pm 0.00$ & $02 \pm 0.00$ & $4.16 \mathrm{E}-04 \pm 0$. & $9.93 \mathrm{E}-04 \pm 0.00$ & $1.03 \mathrm{E}-03 \pm 0.0$ \\
\hline Clo1313_0689 & & & $4.02 E-03 \pm 0.00$ & $4.27 E-02 \pm 0.00$ & $1.38 \mathrm{E}-02 \pm 0.00$ & $3.28 \mathrm{E}-02 \pm 0.01$ & $1.88 \mathrm{E}-02 \pm 0.01$ & $2.67 \mathrm{E}-02 \pm 0$ \\
\hline Clo1313_0563 & & GH30,C & $1.60 \mathrm{E}-02 \pm 0.00$ & $8.53 \mathrm{E}-02 \pm 0.01$ & $1.23 \mathrm{E}-02 \pm 0.00$ & $3.42 \mathrm{E}-03 \pm 0.00$ & $8.75 \mathrm{E}-03 \pm 0.00$ & $8.82 \mathrm{E}-03 \pm 0$ \\
\hline Clo1313_1959 & & GH18 & $1.31 \mathrm{E}-02 \pm 0.00$ & $7.77 E-03 \pm 0.00$ & $1.22 \mathrm{E}-02 \pm 0.01$ & $2.89 \mathrm{E}-03 \pm 0.00$ & $7.62 E-03 \pm 0.00$ & $6.05 \mathrm{E}-03 \pm 0.00$ \\
\hline Clo1313_1983 & & СВВ 35, & $7.82 \mathrm{E}-03 \pm 0.00$ & $6.20 \mathrm{E}-03 \pm 0.00$ & $1.17 \mathrm{E}-02 \pm 0.00$ & $1.74 \mathrm{E}-03 \pm 0.00$ & $1.67 \mathrm{E}-03 \pm 0.00$ & $2.42 \mathrm{E}-03 \pm 0$ \\
\hline Clo1313_1990 & & & $2.33 \mathrm{E}-02 \pm 0.01$ & $1.40 \mathrm{E}-02 \pm 0.00$ & $2 \pm 0.01$ & $1.49 \mathrm{E}-02 \pm 0.00$ & $1.30 \mathrm{E}-02 \pm 0.00$ & $5.04 \mathrm{E}-02 \pm 0$ \\
\hline $\begin{array}{ll}\text { Clo13 } \\
\end{array}$ & & GH30,CBM42, & $3.96 \mathrm{E}-03 \pm 0.00$ & $3 \pm 0.00$ & $22 \pm 0.00$ & $3 \pm 0.00$ & $4.98 \mathrm{E}-03 \pm 0.00$ & $4.06 E-03 \pm 0$ \\
\hline $\begin{array}{ll}\text { Clo131 } \\
\end{array}$ & & GH39,CBM35, & $6.83 \mathrm{E}-02 \pm 0.01$ & $2.20 \mathrm{E}-02 \pm 0.00$ & $9.62 E-03 \pm 0.00$ & $9.60 \mathrm{E}-04 \pm 0.00$ & $1.98 \mathrm{E}-03 \pm 0.00$ & $4.99 \mathrm{E}-03 \pm 0.0$ \\
\hline Clo1313_0987 & & GH43,CBM6,C & $6.17 \mathrm{E}-02 \pm 0.01$ & $2.28 \mathrm{E}-02 \pm 0.00$ & $9.29 \mathrm{E}-03 \pm 0.00$ & $1.29 \mathrm{E}-03 \pm 0$ & $9.72 \mathrm{E}-03 \pm 0.01$ & $4.28 \mathrm{E}-03 \pm 0$ \\
\hline Clo13. & & & $1.73 \mathrm{E}-03 \pm 0.00$ & $2 \pm 0.00$ & $3 \pm 0.00$ & $8.70 \mathrm{E}-03 \pm$ & $5.05 \mathrm{E}-03 \pm 0.00$ & $1.20 \mathrm{E}-02 \pm 0$ \\
\hline \begin{tabular}{|ll} 
Clo1313_0685 \\
\end{tabular} & & & $2.86 \mathrm{E}-03 \pm 0.00$ & $02 \pm 0.01$ & $7.88 \mathrm{E}-03 \pm 0.00$ & $1.75 \mathrm{E}-02 \pm 0.00$ & $1.49 \mathrm{E}-02 \pm 0.01$ & $1.96 \mathrm{E}-02 \pm 0.0$ \\
\hline Clo13 & & & $7.30 \mathrm{E}-03 \pm 0.00$ & $4.44 \mathrm{E}-03 \pm 0.00$ & $6.46 \mathrm{E}-03 \pm 0.00$ & $3.06 E-04 \pm 0.00$ & $2.67 \mathrm{E}-04 \pm 0.00$ & $5.63 \mathrm{E}-04 \pm 0$ \\
\hline 2857 & & H43,CBM6 & $2.43 E-02 \pm 0.00$ & $1.47 E-02 \pm 0.00$ & $=03 \pm 0.00$ & $1.19 \mathrm{E}-04 \pm 0$ & $1.38 \mathrm{E}-03 \pm 0.00$ & $3.23 \mathrm{E}-04 \pm 0$ \\
\hline Clo1313_1564 & & & $3 \pm 0.00$ & \pm 0.00 & $3 \pm 0.01$ & \pm 0.00 & $4.72 \mathrm{E}-03 \pm 0.00$ & $2.08 \mathrm{E}-03 \pm 0$. \\
\hline Clo1313_2022 & & GH16 & $2.58 \mathrm{E}-02 \pm 0.01$ & $1.39 \mathrm{E}-02 \pm 0.00$ & $5.01 E-03 \pm 0.00$ & $8.56 \mathrm{E}-03 \pm 0.00$ & $6.71 \mathrm{E}-03 \pm 0.00$ & $2.88 \mathrm{E}-03 \pm 0.0$ \\
\hline Clo1313_1424 & & $3, \mathrm{CE} 3$ & $1.47 \mathrm{E}-03 \pm 0.00$ & $3.01 \mathrm{E}-03 \pm 0.00$ & $03 \pm 0.00$ & $2.48 \mathrm{E}-03 \pm 0.00$ & $2.29 \mathrm{E}-03 \pm 0.00$ & $7.42 \mathrm{E}-02 \pm 0$ \\
\hline Clo131 & & & $3.89 \mathrm{E}-05 \pm 0.00$ & $2.09 \mathrm{E}-04 \pm 0$ & $03 \pm 0.00$ & $1.73 \mathrm{E}-03 \pm$ & $1.25 \mathrm{E}-03 \pm 0.00$ & $2.74 \mathrm{E}-03 \pm 0$ \\
\hline \begin{tabular}{|l|l|l} 
Clo1313_1786 \\
\end{tabular} & & GH124 & $7.30 E-03 \pm 0.01$ & $2 \pm 0.00$ & $3 \pm 0.00$ & $4 \pm 0.00$ & $7.67 \mathrm{E}-04 \pm 0.00$ & $1.33 \mathrm{E}-03 \pm 0$ \\
\hline Clo1313_2188 & & & $8.88 \mathrm{E}-05 \pm 0.00$ & $7.34 \mathrm{E}-05 \pm 0.00$ & $1.62 \mathrm{E}-03 \pm 0.00$ & $1.40 \mathrm{E}-04 \pm 0.00$ & $1.26 \mathrm{E}-04 \pm 0.00$ & $1.28 \mathrm{E}-04 \pm 0.00$ \\
\hline $\begin{array}{ll}\text { Clo13 } \\
\end{array}$ & & & $2.86 \mathrm{E}-03 \pm 0.00$ & $04 \pm 0.00$ & $9.57 \mathrm{E}-04 \pm 0.00$ & $4.79 \mathrm{E}-03 \pm 0$ & $03 \pm 0.6$ & $9.79 \mathrm{E}-03 \pm$ \\
\hline Clo1313_0693 & & 2,CBM35,CE12 & $1.92 \mathrm{E}-04 \pm 0.00$ & $1.09 \mathrm{E}-04 \pm 0.00$ & $34 \pm 0.00$ & $1.84 \mathrm{E}-04 \pm 0.00$ & $7.09 \mathrm{E}-05 \pm 0.00$ & $-03 \pm 0$ \\
\hline Clo1313_2858 & & СЕ1,СВME & $4.24 \mathrm{E}-03 \pm 0.00$ & $1.85 \mathrm{E}-03 \pm 0.00$ & $2.88 \mathrm{E}-04 \pm 0.00$ & $1.33 \mathrm{E}-04 \pm 0.00$ & $3.30 \mathrm{E}-04 \pm 0.00$ & $5.54 \mathrm{E}-04 \pm 0$ \\
\hline Clo1313_2859 & & СвM6 & $3.54 \mathrm{E}-03 \pm 0.00$ & $3.82 \mathrm{E}-04 \pm 0.00$ & $2.79 E-04 \pm 0.00$ & $1.84 \mathrm{E}-05 \pm 0.00$ & $1.94 \mathrm{E}-04 \pm 0.00$ & $1.00 \mathrm{E}-04 \pm 0.00$ \\
\hline Clo13 & $26 / 5$ & $\mathrm{GH} 26 \mathrm{G}$ & $2.14 \mathrm{E}-03 \pm 0.00$ & 2.68 & $2.40 \mathrm{E}-04 \pm 0.0$ & $2.13 \mathrm{E}-03 \pm$ & $3 \pm$ & 425 \\
\hline Clo1313_2794 & & $=$ & $3.70 \mathrm{E}-04 \pm 0.00$ & \pm 0.00 & $4 \pm 0.00$ & $5 \pm 0.00$ & $4.90 \mathrm{E}-04 \pm 0.00$ & $5.39 \mathrm{E}-04 \pm 0$ \\
\hline \begin{tabular}{|ll} 
Clo1313_2861 \\
\end{tabular} & & GH2,СBM6 & $7.83 \mathrm{E}-04 \pm 0.00$ & $2.07 E-04 \pm 0.00$ & $6.99 \mathrm{E}-05 \pm 0.00$ & $6.04 \mathrm{E}-06 \pm 0.00$ & $1.00 \mathrm{E}-04 \pm 0.00$ & $8.90 \mathrm{E}-06 \pm 0$ \\
\hline $\begin{array}{ll}\text { Clo1313 } \\
\end{array}$ & & GH43,CBM6 & $4.10 \mathrm{E}-04 \pm 0.00$ & $2.34 \mathrm{E}-04 \pm 0.00$ & $0.00 E+00 \pm$ & $0.00 E+00 \pm 0.00$ & $2.03 \mathrm{E}-04 \pm 0.00$ & $0.00 \mathrm{E}+00 \pm 0$ \\
\hline & & onves & $4 \pm$ & $0.00 E+00=$ & $.00 E+00 \pm$ & $7.56 \mathrm{E}-05 \pm$ & $1.83 \mathrm{E}-04 \pm$ & $5.68 \mathrm{t}-05 \mathrm{f}$ \\
\hline
\end{tabular}

Fig. 5 Cellulosomal subunit composition. Subunit compositions of the different cellulosomes were analyzed by label-free LC-MS/MS mass spectrometry. The intensities were normalized by intensity-based absolute quantification (iBAQ) method. The resultant iBAQ intensities of type I dockerin-containing subunits were divided by the iBAQ intensity of ScaA in each sample, thereby generating a relative abundance index. Average and standard deviations of duplicate samples of CB- and MCC-derived cellulosomes and triplicates of glucose-, alSG-, alCS-, and acCS-derived cellulosomes were analyzed. The 20 most abundant subunits in each sample were rated by a colored scale. Gene ID and CAZY annotation of the subunits are mentioned in the table too. GH, glycoside hydrolase; CBM, carbohydrate-binding module; CE, carbohydrate esterase

lowest level in CB-derived cellulosomes. Nevertheless, these differences were not statistically significant (A similar pattern was reported for C. thermocellum ATCC
27450 [26]). A different pattern was found for CbhA; however, which revealed higher relative abundance in the CB- and glucose-derived cellulosomes compared to 


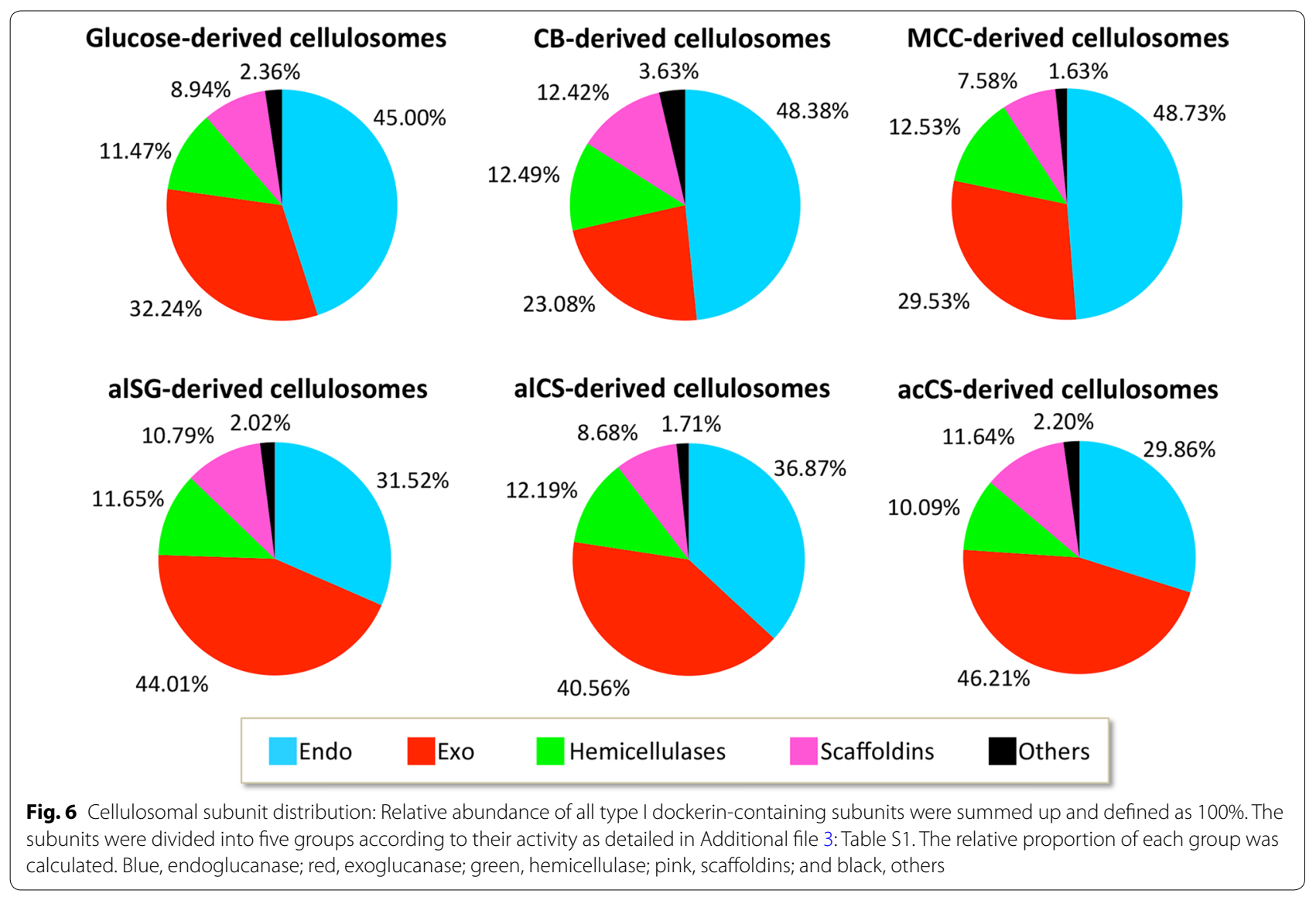

the MCC- and the lignocellulosic biomass-derived cellulosomes. Cel9 $\mathrm{K}$ and $\mathrm{CbhA}$ are tandem genes, containing a similar type of modular structure (except the lack of X1-like domains and the CBM3 domain in Cel9K), with $94 \%$ identity among the modules, and therefore suggested to arose by gene duplication [63]. Due to the similarity in enzyme structure, it would be tempting to assume a similar function. Thus, the non-similar abundance pattern of the two proteins was somewhat surprising. The different role of CbhA and Cel9 $\mathrm{K}$ remains to be explored.

\section{Endoglucanases}

Among the different cellulosomal samples examined in this work, the twenty most abundant catalytic endoglucanase subunits always included the following enzymes: Cel9Q, Cel9R, Cel5G, Cel9W, Cel9U, Cel9V, Cel9T, Cel5B, and Cel9/44J. In recent preliminary data (Additional file 4: Table S2), Cel9/44J and Cel9D exhibited the highest endoglucanase activity of $25 \mathrm{C}$. thermocellum cellulosomal subunits examined. Surprisingly, Cel9D showed low relative abundance and therefore did not appear in the latter list in any of the analyzed samples. The data support the above claim that the cellulosomal subunit composition, derived from cells grown on the different substrates, is not necessarily optimized for efficient substrate hydrolysis.

\section{Type I dockerin-to-ScaA ratio}

Type I dockerin-to-ScaA (type I dockerin/scaffoldin) ratio was calculated by summing up the relative abundance values for all of the type I dockerin-containing subunits in each sample. The ratio was almost double in the MCC- and glucose-derived cellulosomes (22.7 and 20.9 molecules per ScaA, respectively) compared to those of the alSG- and acCS-derived cellulosomes (11.2 and 10.1 molecules per ScaA, respectively) and higher than the alCS- and CB-derived cellulosomes (14.3 and 16.5 molecules per ScaA, respectively). The results revealed higher numbers of cellulosomal subunits per scaffoldin in the MCC- and glucose-derived cellulosomes, which might thus explain the observed higher hydrolytic activity of the latter cellulosomes.

\section{Soluble carbohydrate-active enzymes}

Besides cellulosomal (dockerin-containing) enzymes, C. thermocellum produces a repertoire of soluble carbohydrate-active enzymes without dockerins as well. In order to characterize these non-cellulosomal enzymes 
and their relative content in the different samples, MS results were analyzed and compared to the C. thermocellum DSM1313 CAZY database (for GH/PL/GT/CE/ CBM containing enzymes). In total, 28 additional noncellulosomal carbohydrate-active enzymes were identified in the various cellulosome samples (Additional file 5: Table S3). The presence of un-complexed subunits was also supported by the detection of the structural scaffoldin ScaG. The present results are in line with previously described reports for C. clariflavum cellulosomes [40]. The detection of soluble carbohydrate-active enzymes in the high-molecular-weight fractions may reflect the result of non-specific interactions or unknown specific interactions that are not mediated by cohesin-dockerin interactions.

\section{Unique expression patterns}

Three cellulosomal subunits were significantly upregulated in cellulosomes derived from the defined cellulosic substrates, that is, glucose-, cellobiose-, and MCC-derived cellulosomes: Clo1313_1305 (CBM22-GH10-CBM22-dockerin-CE1), Clo1313_1563 (GH43-CBM13-dockerin), and Clo1313_0501 (PL1dockerin-CBM35). Comparison of cellulosomes derived from the soluble substrates (i.e., cellobiose and glucose) versus those from the insoluble substrates revealed significant upregulation of the non-cellulosomal protein Clo1313_0397 (SLH-CBM54-GH16-CBM4CBM4-CBM4-CBM4-CBM4) and the cellulosomal subunit Clo1313_2857 (GH43-CBM6-dockerin). The cellulosomal subunit Clo1313_2479 (containing no identified CAZy module) was significantly downregulated. The role of these enzymes is as yet unknown.

\section{Comparison of $\boldsymbol{C}$. thermocellum strains}

The 'classic' reference, $C$. thermocellum strain ATCC 27405 , was intensively studied in the past at the proteomic and transcriptomic level, while growing the cells on several different carbon sources [21, 25, 28, 39]. A recent release of the complete C. thermocellum strain DSM 1313 genome sequence [47] enabled differential omic studies, including both transcriptome and proteome. Moreover, the only successful gene-directed mutagenesis has been reported for strain DSM 1313, while strain ATCC 27405 is not easily amenable to genetic manipulations [64]. The composition of MCC-derived cellulosomes from strain DSM1313 reported here showed differences in subunit composition compared to that previously described for equivalent preparations from strain ATCC 27405. At least nine undetected cellulosomal enzymes in strain ATCC 27405 cellulosome [25] were detected in this study using the DSM 1313 strain: Clo1313_3023
(Cel9U, which was also detected earlier by Zverlov et al. [65]), Clo1313_2793 (GH39), Clo1313_1564 (GH81), Clo1313_0501 (PL10, Clo1313_2794, Clo1313_2858 (CE1), Clo1313_2859 (GH141), Clo1313_2860 (GH43), and Clo1313_2861 (GH2) (Fig. 5). The last five proteins showed relatively low but measurable relative abundance. In this context, Clo1313_2858, Clo1313_2859, Clo1313_2860, and Clo1313_2861 are located on the same operon. The orthologous operon in strain ATCC 27405 was found to be disrupted by a putative $2419 \mathrm{bp}$ insertion sequence element located within the $5^{\prime}$ end of the Clo1313_2861 orthologue (annotated as two different genes: Cthe_2197 and Cthe2200). Such an insertion sequence does not exist in the DSM 1313 strain. The most abundant endoglucanases in the DSM1313 cellulosome, i.e., Cel9Q, Cel9R, Cel5G, and Cel9W, showed 3.7-fold to fivefold higher relative abundance, compared to the strain ATCC 27405-derived cellulosome [25]. In contrast, Cel8A, and Cel5E showed relatively lower abundance (fivefold and tenfold, respectively) in the DSM1313 cellulosomes, compared to those of strain ATCC 27405. Xyn11A (Clo1313_0521), which was the third most abundant protein in the ATCC 27405 cellulosome system, showed fivefold lower relative abundance in the DSM1313 system. We assume that higher expression of the Xyn11A homologue in ATCC 27405 (Cthe_2972) might be explained by a different gene organization in the two $C$. thermocellum genomes. While the $x y n 11 A$ gene of DSM 1313 is a second ORF of a two-cistronic operon ( $x y n 11 B /$ Clo1313_0522-xyn11A/Clo1313_0521), the ATCC 27405 genome has only one gene, $x y n 11 A$, while a $x y n 11 B$ homologue appears to be omitted from this genome.

\section{Conclusions}

Our results demonstrate that cells grown on a given lignocellulosic substrate do not necessarily produce cellulosomes that exhibit enhanced activity levels on that particular substrate. Surprisingly, MCC- and glucosederived cellulosomes showed superior performance even towards degradation of complex lignocellulosic substrates. The latter cellulosome preparations exhibited distinctive characteristics, e.g., elevated endoglucanase-to-exoglucanase ratios and enzyme-versus-ScaA ratios. The most abundant subunits in all tested cellulosomes included Cel48S, Cel9K, Cel9Q, Cel9R, and Cel5G, indicating their preferential contribution and importance to deconstruction of complex cellulosic substrates. Our results should be implemented in the future for fabrication of efficient designer cellulosomes, for formulation of recombinant cellulolytic cocktails based on $C$. thermocellum enzymes or for engineering $C$. thermocellum strains with improved lignocellulosic biomass-converting abilities. 


\section{Additional files}

Additional file 1: Figure S1. Purification profile of the different cellulosomes by Gel filtration chromatography. C. thermocellum growth media were centrifuged $(10,900 \mathrm{~g}, 7 \mathrm{~min})$, and the supernatant fluids were carefully removed from the pellet and concentrated 40 times using a Pellicon XL biomax 300 cassette (Millipore, Cat. No. PXB300C50). Concentrated samples were fractionated by size exclusion chromatography using a SuperdexS-200 prep grade 16/60 gel filtration column (GE Healthcare). (A) Chromatogram of glucose-derived cellulosomes (B) Chromatogram of CB-derived cellulosomes (C) Chromatogram of MCC-derived cellulosomes (D) Chromatogram of alSG-derived cellulosomes (E) Chromatogram of alCS-derived cellulosomes (F) Chromatogram of acCS-derived cellulosomes. Fractions containing the cellulosomes (according to SDS-PAGE analysis) are marked by black arrows. All cellulosomes-containing fractions were eluted immediately after void value due to the separation range of the column.

Additional file 2: Figure S2. Calibration of the near-linear range of the various substrate hydrolyses. Increased cellulosome dosages were applied on (A) 7\% microcrystalline cellulose [MCC], (B) 5\% alkaline-pretreated switch grass [alSG], (C) 5\% alkaline-pretreated corn stover [alCS] and (D) 5\% dilute acid-pretreated corn stover [acCS], and the samples were incubated overnight at $70^{\circ} \mathrm{C}$. Released sugar concentrations were measured by dinitrosalicylic acid (DNS) method, as previously described [36] All assays were performed with the addition of $0.33 \mathrm{mg} / \mathrm{ml}$ equivalent of Thermoanaerobacter brockii B-glucosidase (CgIT) in order to prevent feedback inhibition. Enzyme loadings of 20,50, 3 and $50 \mathrm{\mu g} / \mathrm{ml}$ for MCC, aISG, alCS and acCS hydrolysis assays, respectively, were chosen for activity measurements (Black arrows).

Additional file 3: Table S1. Functional classes distribution of $C$. thermocellum DSM 1313 cellulosomal subunits. Cellulosomal subunits detected in the C. themocellum DSM 1313 proteome were sorted into five functional classes: endoglucanases, exoglucanases, hemicellulases, scaffoldins and others.

Additional file 4: Table S2. Activities of C. thermocellum cellulosomal enzymes. Recombinant $C$. themocellum cellulosomal (type I dockerincontaining) enzymes were a kind gift of CelDezyner Ltd. (Rehovot, Israel). Activity assays were conducted in a final volume of $1 \mathrm{ml}$, containing $50 \mathrm{mM}$ acetate buffer, $1 \%$ carboxymethyl cellulose (sodium salt, low viscosity CMC, BDH chemicals) and $7 \mathrm{nM}$ enzyme. Samples were incubated with shaking for $3 \mathrm{~h}$ at $60^{\circ} \mathrm{C}$. Released soluble sugar (reducing ends) concentrations were analyzed by the dinitrosalicylic acid (DNS) method, as previously described [36]. Final soluble sugar concentrations were determined against a glucose calibration curve, and CMCase activities [ $\mu M$ reducing ends. $u \mathrm{~mol}$ enzyme $\left.{ }^{-1} \cdot \mathrm{min}^{-1}\right]$ were calculated. ${ }^{*} \mathrm{~A}$ thermostable clone of Cel8A [66] was used.

Additional file 5: Table S3. Soluble (non-cellulosomal) carbohydrateactive enzyme composition. Soluble (dockerin-lacking) carbohydrateactive enzyme compositions of the different cellulosomes were analyzed by label-free LC-MS/MS mass spectrometry. The intensities were normalized by the intensity-based absolute quantification (BAA) method. The resultant $\mathrm{iBAQ}$ intensities were divided by the iBAQ intensity of ScaA in each sample, thereby generating a relative abundance index. Standard deviations of duplicate samples of CB- and MCC-derived cellulosomes and triplicates of glucose-, alSG-, alCS-, and acCS-derived cellulosomes were analyzed. Gene ID and CAZy annotation of the subunits are designated. Acronyms: GH, glycoside hydrolase; CBM, carbohydrate-binding module; $\mathrm{CE}$, carbohydrate esterase; GT, glycosyl transferase.

\section{Abbreviations}

CB: cellobiose; MCC: microcrystalline cellulose; alSG: alkaline-pretreated switch grass; alCS: alkaline-pretreated corn stover; acCS: dilute acid-pretreated corn stover; MS: mass spectrometry; iBAQ: intensity-based absolute quantification; CBM: carbohydrate-binding module; GH: glycoside hydrolase; CE: carbohydrate esterase; GT: glycosyl transferase; PL: polysaccharide lyase; Sca: scaffoldin;
SLH: S-layer homology; Xyn: xylanase; SDS-PAGE: sodium dodecyl sulfate polyacrylamide gel electrophoresis.

\section{Authors' contributions}

$S Y, Y H, E M$, and EAB designed the research. SY performed the experiments and analyzed the results. SY, YB, and MS purified the cellulosomes. IB and RL analyzed the genome data. SY and BD analyzed mass spectrometry data. SY, $E M$, and $E A B$ wrote the manuscript. All authors read and approved the final manuscript.

\section{Author details \\ ${ }^{1}$ Department of Plant Pathology and Microbiology, Robert H. Smith Faculty of Agriculture, Food and Environment, The Advanced School for Environ- mental Studies, The Hebrew University of Jerusalem, 76100 Rehovot, Israel. ${ }^{2}$ Designer Energy Ltd, 2 Bergman Street, Rehovot, Israel. ${ }^{3}$ Bio-Nano Unit, Chemical Research Support, The Weizmann Institute of Science, 761000 Reho- vot, Israel. ${ }^{4}$ Department of Biomolecular Sciences, The Weizmann Institute of Science, 76100 Rehovot, Israel. ${ }^{5}$ Department of Molecular Microbiology and Biotechnology, Tel Aviv University, Ramat Aviv, Israel.}

\section{Acknowledgements}

The authors appreciate the contribution of the Smoler Proteomics Center, Faculty of Biology, Technion, Israel, and especially the contribution of Keren Bendalak for the proteomic analysis. The authors also acknowledge CelDezyner LTD, Rehovot, Israel, for supplying thermostable $\beta$-glucosidase samples and $C$. thermocellum recombinant enzymes.

\section{Competing interests}

The authors declare that they have no competing interests.

\section{Availability of data and materials}

Not applicable.

\section{Consent for publication}

Not applicable.

\section{Ethics approval and consent to participate}

Not applicable.

\section{Funding}

This research was supported by a research grant from the Ministry of Science, Technology \& Space, Israel. In addition, Grant No. 1349 from the Israel Science Foundation (ISF), Jerusalem, Israel, is gratefully acknowledged. The authors also appreciate the support of the European Union, Area NMP.2013.1.1-2: self-assembly of naturally occurring nanosystems: CellulosomePlus Project Number: 604530 and European Union Horizon 2020 contract: Sustainable production of next generation biofuels from waste streams: Waste2Fuels. EAB is the incumbent of The Maynard I. and Elaine Wishner Chair of Bio-organic Chemistry.

\section{Publisher's Note}

Springer Nature remains neutral with regard to jurisdictional claims in published maps and institutional affiliations.

Received: 8 June 2017 Accepted: 7 September 2017 Published online: 18 September 2017

\section{References}

1. Goldemberg J. Ethanol for a sustainable energy future. Science. 2007:315:808-10

2. Hadar Y. Sources for lignocellulosic raw materials for the production of ethanol. In: Faraco V, editor. Lignocellulose conversion. Berlin: Springer; 2013. p. 21-39.

3. Sun Y, Cheng J. Hydrolysis of lignocellulosic materials for ethanol production: a review. Bioresour Technol. 2002;83:1-11. 
4. Bayer EA, Lamed R, Himmel ME. The potential of cellulases and cellulosomes for cellulosic waste management. Curr Opin Biotechnol. 2007; 18:237-45

5. Mittal A, Decker SR. Special issue: application of biotechnology for biofuels: transforming biomass to biofuels. 3Biotech. 2013;3:341-3.

6. Reijnders $L$. Ethanol production from crop residues and soil organic carbon. Resour Conserv Recycl. 2008:52:653-8.

7. Pettolino FA, Walsh C, Fincher GB, Bacic A. Determining the polysaccharide composition of plant cell walls. Nat Protoc. 2012;7:1590-607.

8. Pauly M, Keegstra K. Cell-wall carbohydrates and their modification as a resource for biofuels. Plant J. 2008;54:559-68.

9. Viikari L, Vehmaanperä J, Koivula A. Lignocellulosic ethanol: from science to industry. Biomass Bioenerg. 2012;46:13-24.

10. Klein-Marcuschamer D, Oleskowicz-Popiel P, Simmons BA, Blanch HW. The challenge of enzyme cost in the production of lignocellulosic biofuels. Biotechnol Bioeng. 2012;109:1083-7.

11. Horn SJ, Vaaje-Kolstad G, Westereng B, Eijsink VG. Novel enzymes for the degradation of cellulose. Biotechnol Biofuels. 2012;5:45

12. Himmel ME, Xu Q, Luo Y, Ding S-Y, Lamed R, Bayer EA. Microbial enzyme systems for biomass conversion: emerging paradigms. Biofuels. 2010;1:323-41.

13. Koeck DE, Koellmeier T, Zverlov W, LiebI W, Schwarz WH. Differences in biomass degradation between newly isolated environmental strains of Clostridium thermocellum and heterogeneity in the size of the cellulosomal scaffoldin. Syst Appl Microbiol. 2015;38:424-32.

14. Fontes CMGA, Gilbert HJ. Cellulosomes: highly efficient nanomachines designed to deconstruct plant cell wall complex carbohydrates. Annu Rev Biochem. 2010;79:655-81.

15. Demain AL, Newcomb M, Wu JHD. Cellulase, clostridia, and ethanol. Microbiol Mol Biol Rev. 2005;69:124-54.

16. Lynd LR, Weimer PJ, Van ZyI WH, Pretorius IS. Microbial cellulose utilization: fundamentals and biotechnology. Microbiol Mol Biol Rev. 2002:66:506-77.

17. Lynd LR, Van ZyI WH, Mcbride JE, Laser M. Consolidated bioprocessing of cellulosic biomass: an update. Curr Opin Biotechnol. 2005;16:577-83.

18. Bayer EA, Lamed R, White BA, Flint HJ. From cellulosomes to cellulosomics. Chem Rec. 2008:8:364-77.

19. Kosugi A, Murashima K, Tamaru Y, Doi RH. Cell-surface-anchoring role of $\mathrm{N}$-terminal surface layer homology domains of Clostridium cellulovorans EngE. J Bacteriol. 2002;184:884-8.

20. Fierobe H, Bayer EA, Tardif C, Czjzek M, Mechaly A, Lamed R, et al. Degradation of cellulose substrates by cellulosome chimeras. J Biol Chem. 2002;277:49621-30.

21. Raman B, Mckeown CK Jr, Rodriguez M, Brown SD, Mielenz JR. Transcriptomic analysis of Clostridium thermocellum ATCC 27405 cellulose fermentation. BMC Microbiol. 2011:11:134.

22. Hazlewood GP, Davidson K, Laurie JI, Huskisson NS, Gilbert HJ. Gene sequence and properties of Cell, a family E endoglucanase from Clostridium thermocellum. J Gen Microbiol. 1993:139:307-16.

23. Fuchs K, Zverlov W, Velikodvorskaya GA, Lottspeich F, Schwarz WH. Lic16A of Clostridium thermocellum, a non-cellulosomal, highly complex endo- $\beta-1,3$-glucanase bound to the outer cell surface. Microbiology. 2003;149:1021-31.

24. Berger E, Zhang D, Zverlov VV, Schwarz WH. Two noncellulosomal cellulases of Clostridium thermocellum, Cel9l and Cel48Y, hydrolyse crystalline cellulose synergistically. FEMS Microbiol Lett. 2007;268:194-201.

25. Raman B, Pan C, Hurst GB, Rodriguez M, Mckeown CK, Lankford PK, et al. Impact of pretreated Switchgrass and biomass carbohydrates on Clostridium thermocellum ATCC 27405 cellulosome composition: a quantitative proteomic analysis. PLOS ONE. 2009;4:e5271.

26. Gold ND, Martin VJJ. Global view of the Clostridium thermocellum cellulosome revealed by quantitative proteomic analysis. J Bacteriol. 2007;189:6787-95.

27. Wilson CM Jr, Rodriguez M, Johnson CM, Martin SL, Chu TM, Wolfinger $\mathrm{RD}$, et al. Global transcriptome analysis of Clostridium thermocellum ATCC 27405 during growth on dilute acid pretreated Populus and switchgrass. Biotechnol Biofuels. 2013;6:179.

28. Wei H, Fu Y, Magnusson L, Baker JO, Maness P, Xu Q, et al. Comparison of transcriptional profiles of Clostridium thermocellum grown on cellobiose and pretreated yellow poplar using RNA-Seq. Front Microbiol. 2014;5:142.
29. Johnson EA, Bouchot F, Demain AL. Regulation of cellulase formation in Clostridium thermocellum. J Gen Microbiol. 1985;131:2303-8.

30. Hernandez PE. Transport of D-glucose in Clostridium thermocellum ATCC27405. J Gen Appl Microbiol. 1982;28:469-77.

31. Strobel HJ, Caldwell FC, Dawson KA. Carbohydrate transport by the anaerobic thermophile Clostridium thermocellum LQRI. Appl Environ Microbiol. 1995;61:4012-5.

32. loelovich M, Morag E. Study of enzymatic hydrolysis of mild pretreated lignocellulosic biomass. BioResources. 2012;7:1040-52

33. Ioelovich M. Methods for determination of chemical composition of plant biomass. J SITA. 2015;17:208-14.

34. TAPPI. Test method T $222 \mathrm{om}-02$. Acid-insoluble lignin in wood and pulp. Atlanta: TAPPI; 2002.

35. Bayer EA, Kenig R, Lamed R. Adherence of Clostridium thermocellum to cellulose. J Bactertiol. 1983;156:818-27.

36. Miller GL. Use of dinitrosalicylic acid reagent for determination of reducing sugar. Anal Biochem. 1959;31:426-8.

37. Cox J, Mann M. MaxQuant enables high peptide identification rates, individualized p.p.b.-range mass accuracies and proteome-wide protein quantification. Nat Biotechnol. 2008:26:1367-72.

38. Busse D, Li N, Dittmar G, Schuchhardt J, Wolf J, Chen W, et al. Global quantification of mammalian gene expression control. Nature. 2011:473:337-42.

39. Rydzak T, Mcqueen PD, Krokhin OV, Spicer V, Ezzati P, Dwivedi RC, et al. Proteomic analysis of Clostridium thermocellum core metabolism: relative protein expression profiles and growth phase-dependent changes in protein expression. BMC Microbiol. 2012;12:214.

40. Artzi L, Morag E, Barak Y, Lamed R, Bayer EA. Clostridium clariflavum: key cellulosome players are revealed by proteomic analysis. mBio. 2015;6:e00411-5.

41. De Philip P, Lignon S, Tardif C, Page S. Modulation of cellulosome composition in Clostridium cellulolyticum: adaptation to the polysaccharide environment revealed by proteomic and carbohydrate-active enzyme analyses. Proteomics. 2010;10:541-54.

42. Bayer EA, Morag E, Lamed R. The cellulosome-a treasure-trove for biotechnology. Trends Biotechnol. 1994;12:379-86.

43. Lamed R, Kenig R, Setter E, Bayer EA. Major characteristics of the cellulolytic system of Clostridium thermocellum coincide with those of the purified cellulosome. Enzyme Microb Technol. 1985;7:37-41.

44. Lombard V, Ramulu HG, Drula E, Coutinho PM, Henrissat B. The carbohydrate-active enzymes database (CAZy) in 2013. Nucleic Acids Res. 2014:42:D490-5.

45. Brás JLA, Pinheiro BA, Cameron K, Cuskin F, Viegas A, Najmudin S, et al. Diverse specificity of cellulosome attachment to the bacterial cell surface. Sci Rep. 2016;6:38292.

46. Fierobe H-P, Mingardon F, Mechaly A, Belaich A, Rincon MT, Pages S, et al. Action of designer cellulosomes on homogeneous versus complex substrates: controlled incorporation of three distinct enzymes into a defined trifunctional scaffoldin. J Biol Chem. 2005:280:16325-34.

47. Feinberg L, Foden J, Barrett T, Davenport KW, Bruce D, Detter C, et al. Complete genome sequence of the cellulolytic thermophile Clostridium thermocellum DSM1313. J Bacteriol. 2011;193:2906-7.

48. Dassa B, Borovok I, Lamed R, Henrissat B, Coutinho P, Hemme CL, et al. Genome-wide analysis of Acetivibrio cellulolyticus provides a blueprint of an elaborate cellulosome system. BMC Genom. 2012;13:210.

49. Hong W, Zhang J, Feng Y, Mohr G, Lambowitz AM, Cui G, et al. The contribution of cellulosomal scaffoldins to cellulose hydrolysis by Clostridium thermocellum analyzed by using thermotargetrons. Biotechnol Biofuels. 2014:7:1-16.

50. Gerngross UT, Romaniec MPM, Kobayashi T, Huskisson NS, Demain AL. Sequencing of a Clostridium thermocellum gene (cipA) encoding the cellulosomal SL-protein reveals an unusual degree of internal homology. Mol Microbiol. 1993;8:325-34.

51. Ding SY, Liu YS, Zeng Y, Himmel ME, Baker JO, Bayer EA. How does plant cell wall nanoscale architecture correlate with enzymatic digestibility? Science. 2012:338:1055-60.

52. Xu Q, Resch MG, Podkaminer K, Yang S, Baker JO, Donohoe BS, et al. Dramatic performance of Clostridium thermocellum explained by its wide range of cellulase modalities. Sci Adv. 2016;:e1501254.

53. Olson DG, Giannone RJ, Hettich RL, Lynd LR. Role of the CipA scaffoldin protein in cellulose solubilization, as determined by targeted gene 
deletion and complementation in Clostridium thermocellum. J Bacteriol. 2013;195:733-9.

54. Zverlov VV, Klupp M, Krauss J, Schwarz WH. Mutations in the scaffoldin gene, CipA, of Clostridium thermocellum with impaired cellulosome formation and cellulose hydrolysis: insertions of a new transposable element, IS1447, and implications for cellulase synergism on crystalline cellulose. J Bacteriol. 2008;190:4321-7.

55. Krauss J, Zverlov W, Schwarz WH. In vitro reconstitution of the complete Clostridium thermocellum cellulosome and synergistic activity on crystalline cellulose. Appl Environ Microbiol. 2012;78:4301-7.

56. Dror TW, Rolider A, Bayer EA, Lamed R, Shoham Y. Regulation of expression of scaffoldin-related genes in Clostridium thermocellum. J Bacteriol. 2003;185:5109-16.

57. Gerwig GJ, De Waard P, Kamerling JP, Vliegenthart JFG, Morgenstern E, Lamed R, et al. Novel O-linked carbohydrate chains in the cellulase complex (cellulose) of Clostridium thermocellum. 3-O-methyl-N-acetylglucosamine as a constituent of a glycoprotein. J Biol Chem. 1989;264:1027-35.

58. Gerwing GJ, Kamerling JP, Vliegenthart JFG. Morag (Morgenstern) E, Lamed R, Bayer EA. Primary structure of O-linked carbohydrate chains in the cellulosome of different Clostridium thermocellum strains. Eur J Biochem. 1991;196:115-22.

59. Gerwig GJ, Kamerling JP, Vliegenthart JFG, Morag E, Lamed R, Bayer EA. Novel oligosaccharide constituents of the cellulase complex of Bacteroides cellulosolvens. Eur J Biochem. 1992;205:799-808.
60. Gerwig GJ, Kamerling JP, Vliegenthart JFG, Morag E, Lamed R, Bayer EA. The nature of the carbohydrate-peptide linkage region in glycoproteins from the cellulosomes of Clostridium thermocellum and Bacteroides celIulosolvens. J Biol Chem. 1993;268:26956-60.

61. Dror TW, Morag E, Rolider A, Bayer EA, Lamed R, Shoham Y. Regulation of the cellulosomal celS (cel48A) gene of Clostridium thermocellum is growth rate dependent. J Bacteriol. 2003;185:3042-8.

62. Stevenson DM, Weimer PJ. Expression of 17 genes in Clostridium thermocellum ATCC 27405 during fermentation of cellulose or cellobiose in continuous culture. Appl Environ Microbiol. 2005;71:4672-8.

63. McGrath CE, Wilson DB. Endocellulolytic activity of the Clostridium thermocellum Cel9C (formerly CbhA) catalytic domain. Ind Biotechnol. 2008:4:99-104

64. Tripathi SA, Olson DG, Argyros DA, Miller BB, Barrett TF, Murphy DM, et al. Development of pyrF-based genetic system for targeted gene deletion in Clostridium thermocellum and creation of a pta mutant. Appl Environ Microbiol. 2010;76:6591-9.

65. Zverlov VV, Kellermann J, Schwarz WH. Functional subgenomics of Clostridium thermocellum cellulosomal genes: identification of the major catalytic components in the extracellular complex and detection of three new enzymes. Proteomics. 2005;5:3646-53.

66. Anbar M, Gul O, Lamed R, Sezerman UO, Bayer EA. Improved thermostability of Clostridium thermocellum endoglucanase Cel8A by using consensus-guided mutagenesis. Appl Environ Microbiol. 2012;78:3458-64.

\section{Submit your next manuscript to BioMed Central and we will help you at every step:}

- We accept pre-submission inquiries

- Our selector tool helps you to find the most relevant journal

- We provide round the clock customer support

- Convenient online submission

- Thorough peer review

- Inclusion in PubMed and all major indexing services

- Maximum visibility for your research

Submit your manuscript at www.biomedcentral.com/submit
() Biomed Central 